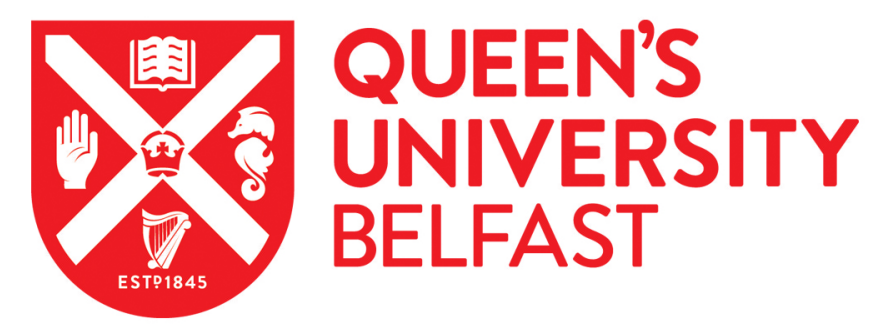

\title{
Fast framing imaging and modelling of vapour formation and discharge initiation in electrolyte solutions
}

Asimakoulas, L., Graham, W., Krcma, F., Dostal, L., Stalder, K. R., \& Field, T. A. (2020). Fast framing imaging and modelling of vapour formation and discharge initiation in electrolyte solutions. Plasma Sources Science and Technology, 29, [035013]. https://doi.org/10.1088/1361-6595/ab2cab

\section{Published in:}

Plasma Sources Science and Technology

\section{Document Version:}

Peer reviewed version

Queen's University Belfast - Research Portal:

Link to publication record in Queen's University Belfast Research Portal

\section{Publisher rights}

Copyright 2019 IOP.

This manuscript is distributed under a Creative Commons Attribution-NonCommercial-NoDerivs License

(https://creativecommons.org/licenses/by-nc-nd/4.0/), which permits distribution and reproduction for non-commercial purposes, provided the author and source are cited.

\section{General rights}

Copyright for the publications made accessible via the Queen's University Belfast Research Portal is retained by the author(s) and / or other copyright owners and it is a condition of accessing these publications that users recognise and abide by the legal requirements associated with these rights.

Take down policy

The Research Portal is Queen's institutional repository that provides access to Queen's research output. Every effort has been made to ensure that content in the Research Portal does not infringe any person's rights, or applicable UK laws. If you discover content in the Research Portal that you believe breaches copyright or violates any law, please contact openaccess@qub.ac.uk. 
ACCEPTED MANUSCRIPT

\title{
Fast framing imaging and modelling of vapour formation and discharge initiation in electrolyte solutions
}

To cite this article before publication: Leonidas Asimakoulas et al 2019 Plasma Sources Sci. Technol. in press https://doi.org/10.1088/1361$\underline{6595 / \mathrm{ab} 2 \mathrm{cab}}$

\author{
Manuscript version: Accepted Manuscript \\ Accepted Manuscript is "the version of the article accepted for publication including all changes made as a result of the peer review process, \\ and which may also include the addition to the article by IOP Publishing of a header, an article ID, a cover sheet and/or an 'Accepted \\ Manuscript' watermark, but excluding any other editing, typesetting or other changes made by IOP Publishing and/or its licensors" \\ This Accepted Manuscript is @ 2019 IOP Publishing Ltd.
}

During the embargo period (the 12 month period from the publication of the Version of Record of this article), the Accepted Manuscript is fully protected by copyright and cannot be reused or reposted elsewhere.

As the Version of Record of this article is going to be / has been published on a subscription basis, this Accepted Manuscript is available for reuse under a CC BY-NC-ND 3.0 licence after the 12 month embargo period.

After the embargo period, everyone is permitted to use copy and redistribute this article for non-commercial purposes only, provided that they adhere to all the terms of the licence https://creativecommons.org/licences/by-nc-nd/3.0

Although reasonable endeavours have been taken to obtain all necessary permissions from third parties to include their copyrighted content within this article, their full citation and copyright line may not be present in this Accepted Manuscript version. Before using any content from this article, please refer to the Version of Record on IOPscience once published for full citation and copyright details, as permissions will likely be required. All third party content is fully copyright protected, unless specifically stated otherwise in the figure caption in the Version of Record.

View the article online for updates and enhancements. 


\title{
Fast framing imaging and modelling of vapour formation and discharge initiation in electrolyte solutions
}

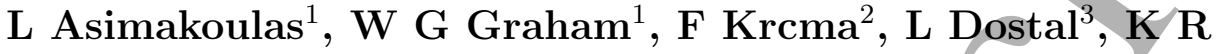 \\ Stalder ${ }^{1}$, T A Field ${ }^{1}$ \\ ${ }^{1}$ Centre for Plasma Physics, School of Maths and Physics, Queens University \\ Belfast, BT7 1NN, UK \\ ${ }^{2}$ Faculty of Chemistry, Brno University of Technology, Purkynova 118, 61200 Brno, \\ Czech Republic \\ 3 Faculty of Electrical and Communication, Brno University of Technology, Technicka \\ 12, 61600 Brno, Czech Republic \\ E-mail: lasimakoulas01@qub.ac.uk, t.field@qub.ac.uk
}

\begin{abstract}
The formation of vapour and initiation of electrical discharges in normal saline and other $\mathrm{NaCl}$ solutions has been observed and modelled. Millisecond pulses of 160 to $-300 \mathrm{~V}$ were applied to a sharp tungsten carbide electrode immersed in the liquid. A fast framing camera was used to observe vapour layer growth around the electrode by shadowgraphy. Images were also taken without backlighting to observe emission accompanying breakdown. The conductivity of the vapour layer has been estimated by comparison of experimentally measured impedances with impedances calculated by finite element modelling of the liquid and vapour around the electrode observed by shadowgraphy. The conductivity of the vapour layer is estimated to vary between $\sim 1$ and $10^{-3} \mathrm{~S} / \mathrm{m}$, which are orders of magnitude higher than expected for water vapour. The reason for the high conductivity is not clear, but may be due to injection of charge carriers into the vapour by corona discharge at the sharp tip and/or the presence of cluster ions in the vapour. Alternatively, the vapour layer may be a foam mixture of high conductivity liquid and low conductivity vapour bubbles. Discharge formation does not occur primarily at the sharp tip of the electrode, but rather at the side. Finite element models of the vapour layer show that the highest electric fields are found close to the sharp tip of the electrode but that the field strength drops rapidly moving away from the tip. By contrast slightly lower, but consistently high, electric fields are often observed between the side of the electrode and the liquid vapour boundary where plasma emission is mostly observed due to the shape of the vapour liquid boundary. The electron number density in the discharge is estimated to be $\sim 10^{21} \mathrm{~m}^{-3}$. There is evidence from the shadowgraphy for different boiling mechanisms; nucleate boiling at lower voltages and film boiling at higher voltages. A rule of thumb based on a simplistic model is suggested to predict the time to discharge based on electrode area, initial current, and electrolyte temperature, density, conductivity and heat capacity.
\end{abstract}

Keywords: electrolyte, plasma discharges, fast framing camera, electric fields, simulations, boiling regimes, bubbles 


\section{Introduction}

There has been considerable interest in electrical discharges in liquids, which have been the subject of a number of recent reviews $[1,2,3,4,5,6,7,8,9,10]$. There are many applications of electrical discharges in liquids including nanoparticle preparation $[11,12,13]$, water remediation $[14,15]$, plasma electrolytic oxidation (PEO) $[16,17,18,19]$, and surgery and biomedicine[20, 21, 22, 23].

Two main liquid discharge initiation mechanisms have been proposed $[24,5,10]$; first, an electron multiplication avalanche mechanism in the liquid phase, and secondly, a mechanism where a vapour bubble is formed and the discharge occurs inside the bubble.

The avalanche mechanism appears to be most prominent at short (ns) timescales with low conductivity liquids and high voltages when there is not enough time for bubbles to form. On the other hand, bubble formation prior to discharge predominates with higher liquid conductivities, lower applied voltages and over longer timescales. Bubbles can form as a result of Joule heating (Ohmic heating) near the electrodes and can also form by electrolysis.

In general, the nature of the liquid, the waveform of the applied voltage and the shape and geometry of the electrode configuration have an impact on the discharge initiation mechanism.

In this paper, we report observations of discharge initiation following bubble formation. Here, the combination of pin-to-plate electrode configuration, large $(\mathrm{cm})$ interelectrode gap, millisecond voltage pulses and high conductivity liquid results in the bubble discharge initiation mechanism.

For some time electrical discharges in sea water have been studied, partly because of their use as sources of acoustic shockwaves. The high conductivity of sea water means bubbles are generally formed prior to discharge. The salt concentration of sea water varies but is typically about $35 \mathrm{~g}$ of salt, mostly $\mathrm{NaCl}$, per litre of salt water [25].

For example, Olson and Sutton studied discharges in sea water and observed vapour bubble formation prior to arc breakdown [26]. Olson and Sutton concluded that 'The dynamics of vapour formation and its relationship to the arc formation process should be measured directly, perhaps through high-speed photographic techniques'. Later Buogo et al. studied discharges in water with the same ionic strength as sea water and similarly concluded 'much is still to be understood regarding the mechanism of the bubble generation, evolution and collapse, which is responsible for a large part of the acoustic energy radiated' [27]. Buogo et al. also concluded that 'as a major step forward in this direction, it is desirable that these processes be investigated by direct observation, i.e. with high-speed camera or other optical techniques, possibly below the millisecond range.'

More recently, Gamaleev et al. highlighted the need of a more detailed study for the initial stages of the bubble formation process prior to microdischarge formation in saline solution [28].

In the past, photomultiplier tubes (PMTs) and single shot iCCDs (intensified 
Charge Coupled Detectors) have been used [29, 30, 31] to investigate underwater plasmas. PMTs provide temporal information for plasma emission, but not spatial information. On the other hand, iCCDs provide spatial information at a single snapshot in time. The spatial evolution of the electrical discharge and bubble formation, can be observed with an iCCD by triggering the camera over multiple electrical discharges at different time delays after some reference point such as the beginning of the voltage pulse. Inevitably, however, shot-to-shot variation between different discharge pulses complicate the interpretation of multiple iCCD images taken in different plasma shots. Thus, it is preferable to record multiple images during a single discharge pulse for simultaneous temporal and spatial observations.

The development of Fast-Framing Cameras (FFCs) with $\mathrm{kHz}$ frame rates and reasonable resolution has provided the opportunity to observe the evolution of individual discharges with a series of images. Many research groups have used FFCs to characterize discharge formation and the effect of discharges on their surrounding environments, for example see [23, 32, 31, 17, 18, 33, 34, 35, 36, 37]. Yoon et al. used an FFC to investigate bubble formation in $\mathrm{RF}$ discharges in $\mathrm{NaCl}$ solutions [32].

In the present investigation, a fast framing camera with microsecond shutter times has been used to record high speed videos of individual plasma discharges. Part of the motivation for the present investigation of electrical breakdown in saline is the use of plasmas in surgery [20, 21]. Normal saline solution is widely used in medicine because its ionic strength is close to that of blood; it is water with $9 \mathrm{~g}$ of $\mathrm{NaCl}$ per litre of solution. As noted above sea water typically has about $35 \mathrm{~g}$ of salt per litre [25]. The present study provides new insights into vapour formation and discharge initiation with a new type of simulation informed by experimental results.

\section{Experimental setup}

The experimental apparatus is shown in figure 1 and is based on the setup that is described in $[38,39,40]$. Briefly, it consists of a power supply that charges a capacitor to a maximum voltage of $300 \mathrm{~V}$ negative polarity. The capacitor is discharged through a negative voltage switch (Behlke HTS 31-06) driven by a TTL pulse from a Stanford DG535 pulse generator. Typically, 1 ms voltage pulses of -140 to $-300 \mathrm{~V}$ were applied to the powered electrode with a pulse repetition frequency of $1 \mathrm{~Hz}$. Different conditions were also explored such as longer $5 \mathrm{~ms}$ voltage pulses. The voltage at the tip and the current flowing to ground were monitored with an oscilloscope, as shown on figure 1. The conductivity of the saline solution was measured using a conductivity meter (Hanna Instruments HI9033) to be $1.61 \mathrm{~S} / \mathrm{m}$ at room temperature.

In previous studies of our group [38, 39, 40], cylindrical rod-type electrodes with diameters of $500 \mu \mathrm{m}$ were powered with similar millisecond medium voltage pulses. In the present study, the rod electrode is replaced with a fine tungsten carbide needle, with a radius of curvature of nominally $500 \mathrm{~nm}$ bought from $\mathrm{F} \cdot \mathrm{S} \cdot \mathrm{T}^{\mathrm{TM}}$ and checked with Scanning Electron Microscopy (SEM) before and after the end of the experiment. Teflon 
tape was used as insulation to ensure that only a small area of the tip was exposed to the liquid. The length of tip in direct contact with the liquid was $\sim 1 \mathrm{~mm}$, which corresponds to an exposed surface area of $\sim 0.6 \mathrm{~mm}^{2}$.

The quartz vessel that contains the electrodes and saline solution can be filled to a total volume of 11 (one litre). The ground electrode is a stainless steel plate of $\sim 60$ $\times 40 \mathrm{~mm}$ with a thickness of $0.5 \mathrm{~mm}$. This electrode rests on the bottom of the quartz vessel at a distance of $40 \mathrm{~mm}$ from the powered tip. The combination of the low pulse repetition rate and the significant volume of liquid ensured that the saline solutions remained at constant temperature.

The optical setup shown in figure 1 includes a Maksutov Cassegrain catadioptric telescope (Questar QM 100) and a fast-framing camera (Photron SA-X2). The distance of the optical bench components was kept the same throughout the experiment but the lens system inside the body of the microscope was adjusted periodically to keep the tip in focus. The resolution of the images depends on the frame rate; most images were taken with $768 \times 688$ pixels at $25 \mathrm{kHz}$. The best resolution that was achieved with this optical set up was $3 \mu \mathrm{m}$.

A halogen tungsten light source (Dedocool) was used as the back-light for the shadowgraphy imaging. It comprises a special reflector that focuses 'an intense amount of light over a highly concentrated area' (shown as a collimating lens in figure 1). It was not always possible to distinguish unambiguously between plasma emission and background light in the shadowgraphy measurements. Therefore, some measurements were made without backlighting where the plasmas emission could be observed clearly. Typical exposure times for the camera were $290 \mathrm{~ns}$ and $1 \mu \mathrm{s}$ with $40 \mu$ s between frames, of course, at $25 \mathrm{kHz}$ frame rate.

\section{Experimental results and discussion}

\subsection{Vaporization of liquid and energy consumption}

Figures 2, 3, 4 and 5 show results obtained with the present experiment when four different nominal voltages were applied to the powered electrode; -160, -200, -250 and $-300 \mathrm{~V}$. The actual potentials measured at the powered electrode in each experiment are shown along with the current flow to ground. The actual electric potentials at the powered electrode are lower than the nominal potentials due to the voltage drop across the resistors on each side of the high voltage switch shown in figure 1 . In fact, the current waveform is reproduced by dividing the observed voltage drop by the total resistance of these resistors, $44.8 \Omega$, which demonstrates that the current into the powered electrode was equal to the current flowing to ground. For each voltage, video supplementary material is available online which shows the development of the shadowgraphy images, measured current and voltage with time simultaneously.

Shadowgraphy images taken with the FFC at different time delays after the application of the pulse are also shown in figures 2, 3, 4 and 5; the images show snapshots 


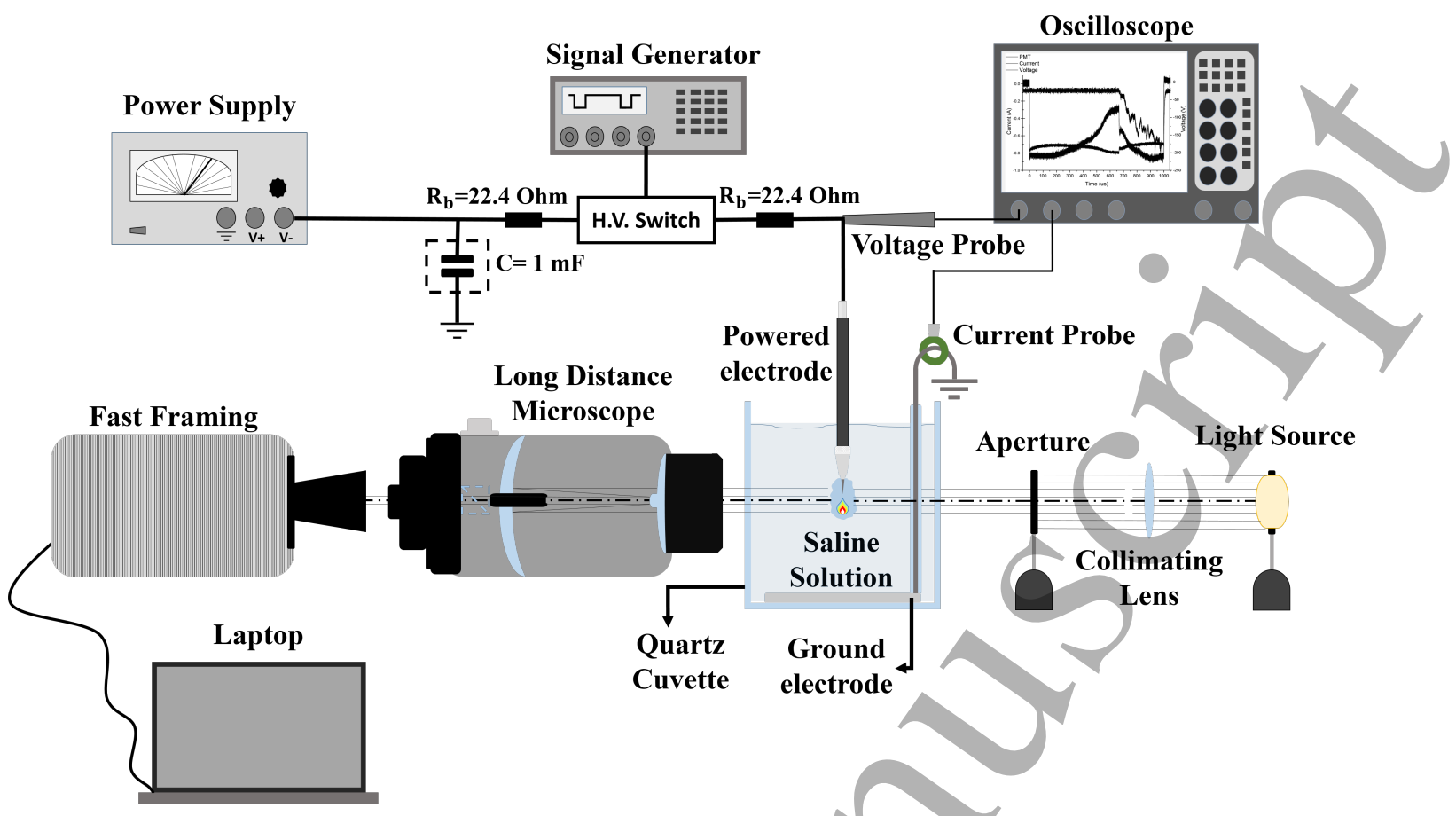

Figure 1. Experimental setup used to generate discharges in saline solutions. SEM images of the tip used are shown in figure 13.

from time zero, when the voltage pulse starts, to the time when the current first drops to close to zero. During this time interval, it is clear from the images that a vapour layer grows around the powered electrode, as has been observed previously [38, 39, 40]. The exact nature of the 'vapour layer' is discussed below; here we note that there is a distinct region in the fast framing images between the electrode and the saline solution, and that there is a clear boundary between this vapour layer and the surrounding saline solution.

The current appears to be made up of two components. One component of the current changes slowly with time and drops to zero as the vapour coverage increases. The second component of the current is made up of short spikes where the current changes rapidly with time. Initially, we attribute the first slowly changing current to ionic conduction and the short spikes we attribute to electric discharges; these attributions are described further below. Spikes are clearly observed, for example, in figure 3, after the current has dropped to zero, viz. between 400 and $450 \mu \mathrm{s}$.

Note that different behaviour is observed in the present investigation at the highest nominal voltage of $-300 \mathrm{~V}$. Clear discharge spikes are observed in the current signal in figure 5 before the current has dropped to half of its initial value at $\sim 100-120 \mu$ s time delay. Plasma emission cannot be unambiguously identified in the shadowgraphy images in figure 5 because of the backlighting, but the spikes in the current waveform clearly indicate electrical discharge at $\sim 100-120 \mu \mathrm{s}$. Weaker spikes also appear to be present between about 50 and $80 \mu \mathrm{s}$ in the $-300 \mathrm{~V}$ waveforms. 


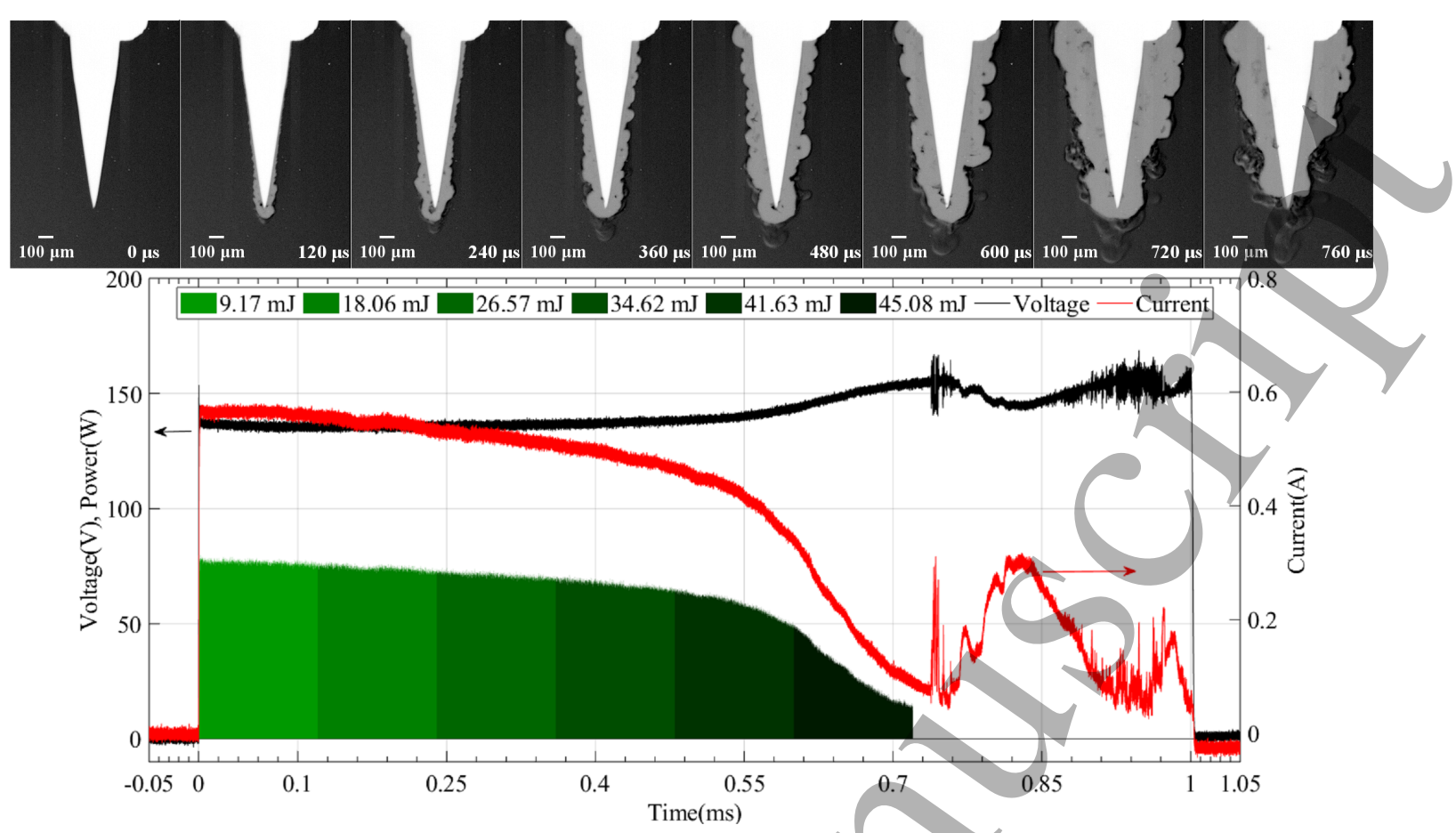

Figure 2. Time dependent shadowgraphy imaging and energy estimation per frame for $-160 \mathrm{~V}$ applied voltage. Fast faming images of the tip, vapour layer and liquid are shown along the top row at the times indicated. Below, electrical potential (black) on the powered electrode and current (red) are shown during the $1 \mathrm{~ms}$ voltage pulse. The line at the top of the green shaded area in the graph is power, the product of the voltage and the current. Both voltage $(\mathrm{V})$ and power $(\mathrm{W})$ values can be read from the left-hand axis scale. The green areas show the integration of power with time to determine energies; $E=\int_{0}^{t_{f}} V I d t$. For instance, the lightest green area starts from 0 $\mu \mathrm{s}$ to the time when the second framé was acquired at $t_{f}=120 \mu$ s and the integrated energy in this window is $9.17 \mathrm{~mJ}$. The same procedure was repeated for each frame up to the frame at $720 \mu$ s always integrating from $0 \mu \mathrm{s}$ up to the frame acquisition time. The different shades of green show the different limits of integration and are used in the key to identify the different energies obtained by integrating power.

In fact, there appear to be some weak discharges before the current drops at -250 $\mathrm{V}$ as well, for example, at $150 \mu \mathrm{s}$ in figure 4 . Images taken in separate measurements at $-250 \mathrm{~V}$ and shown in figure 6 confirm discharge formation before the current drops to zero. These images are discussed below.

Some weak discharges can also be seen in the data for -200 V between 300 and 350 $\mu \mathrm{s}$ in figure 3. By contrast, at $-160 \mathrm{~V}$ there do not appear to be any discharges before the current drops to close to zero between 730 and $750 \mu$ s in figure 2 .

Figure 6 (i) and (ii) show images from two sets of experimental data at $-250 \mathrm{~V}$ (top and middle images) and figure 6 (iii) show simulations of the electric field (lower images). The three images in (i) at the top were taken with backlighting while the three images in (ii) in the middle were taken without back-lighting. The non-illuminated images in the middle row are shown 'in false colour' to represent the intensity of the 

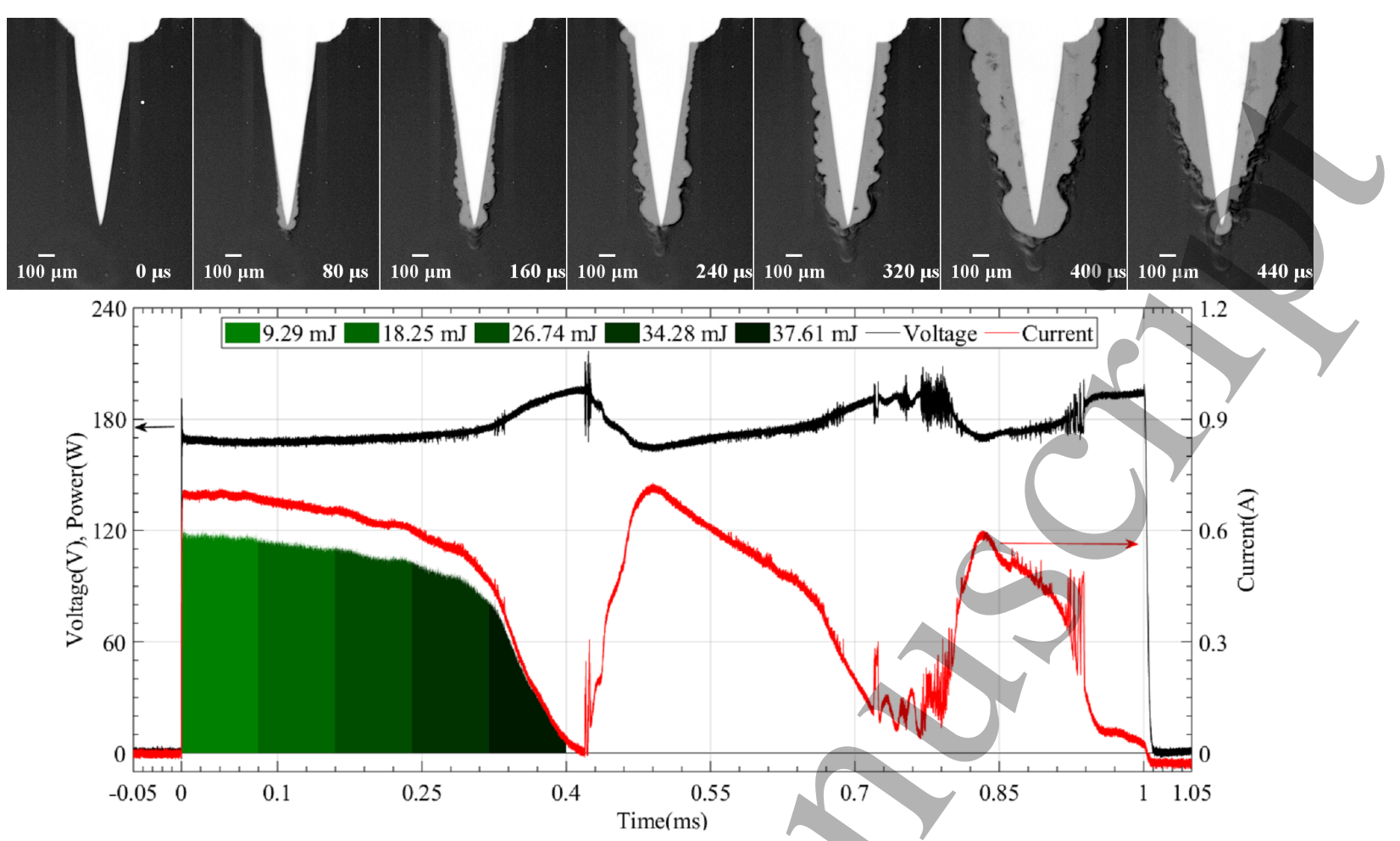

Figure 3. Time dependent shadowgraphy imaging and energy estimation per frame for -200 V applied voltage. Fast faming images of the tip, vapour layer and liquid are shown along the top row at the times indicated. Below, electrical potential (black) on the powered electrode and current (red) are shown during the $1 \mathrm{~ms}$ voltage pulse. The line at the top of the green shaded area in the graph is power, the product of the voltage and the current. Both voltage $(\mathrm{V})$ and power $(\mathrm{W})$ values can be read from the left-hand axis scale. The green areas show the integration of power with time to determine energies; $E=\int_{0}^{t_{f}} V I d t$. For instance, the lightest green area starts from 0 $\mu \mathrm{s}$ to the time when the second frame was acquired at $t_{f}=80 \mu \mathrm{s}$ and the integrated energy in this window is $9.29 \mathrm{~mJ}$. The same procedure was repeated for each frame up to the frame at $400 \mu \mathrm{s}$ always integrating from $0 \mu \mathrm{s}$ up to the frame acquisition time. The different shades of green show the different limits of integration and are used in the key to identify the different energies obtained by integrating power.

discharge emission and are superimposed over a black and white image of the tip so that the location of emission can be seen relative to the position of the tip.

In figure 6 (iii) the bottom row of three images show the calculated magnitude of the electric field in the vapour region. The method of calculation is described in Section 3.5. Briefly, the shape of the interface between the liquid and vapour visible in figure 6 (i), the upper shadowgraphy images, were imported into a modelling package, COMSOL [41], and the electric field was calculated by applying the experimentally measured voltage to the tip. It was assumed that the conductivity of the vapour layer was constant and $2 \times 10^{-3} \mathrm{~S} / \mathrm{m}$. The conductivity of the vapour layer is discussed in Section 3.4 and further details of the electric field calculation process are presented below in Section 3.5 and Appendix A.

The calculated electric field strengths shown in figure 6 (iii) predict that the highest 
electric fields occur close to where emission is observed most intensely in figure 6 (ii), the middle images of the same figure. The highest electric fields are predicted where the liquid vapour interface is closest to the side of the electrode tip.

Note these images were taken with $2.5 \mu$ s between frames, a higher frame rate than the images in figures $2,3,4$ and 5 , but at lower resolution of $128 \times 72$ pixels. Plasma emission was observed at $155,167.5$ and $170 \mu$ s as shown in figure 6 when the current was still above $600 \mathrm{~mA}$. It is evident by a direct comparison of these images that the emission follows the local variations of the liquid and vapour boundaries.

These observations of discharges before the current signal drops towards zero in the present study are, most likely, due to the use of the fine tungsten carbide needle. In similar previous investigations, a cylindrical powered electrode was used with a flat end

Figure 4. Time dependent shadowgraphy imaging and energy estimation per frame for $-250 \mathrm{~V}$ applied voltage. Fast faming images of the tip, vapour layer and liquid are shown along the top row at the times indicated. Below, electrical potential (black) on the powered electrode and current (red) are shown during the 1 ms voltage pulse. The line at the top of the green shaded area in the graph is power, the product of the voltage and the current. Both voltage $(\mathrm{V})$ and power $(\mathrm{W})$ values can be read from the left-hand axis scale. The green areas show the integration of power with time to determine energies; $E=\int_{0}^{t_{f}} V I d t$. For instance, the lightest green area starts from 0 $\mu$ s to the time when the second frame was acquired at $t_{f}=40 \mu$ s and the integrated energy in this window is $7.48 \mathrm{~mJ}$. The same procedure was repeated for each frame up to the frame at $200 \mu$ s always integrating from $0 \mu$ s up to the frame acquisition time. The different shades of green show the different limits of integration and are used in the key to identify the different energies obtained by integrating power.
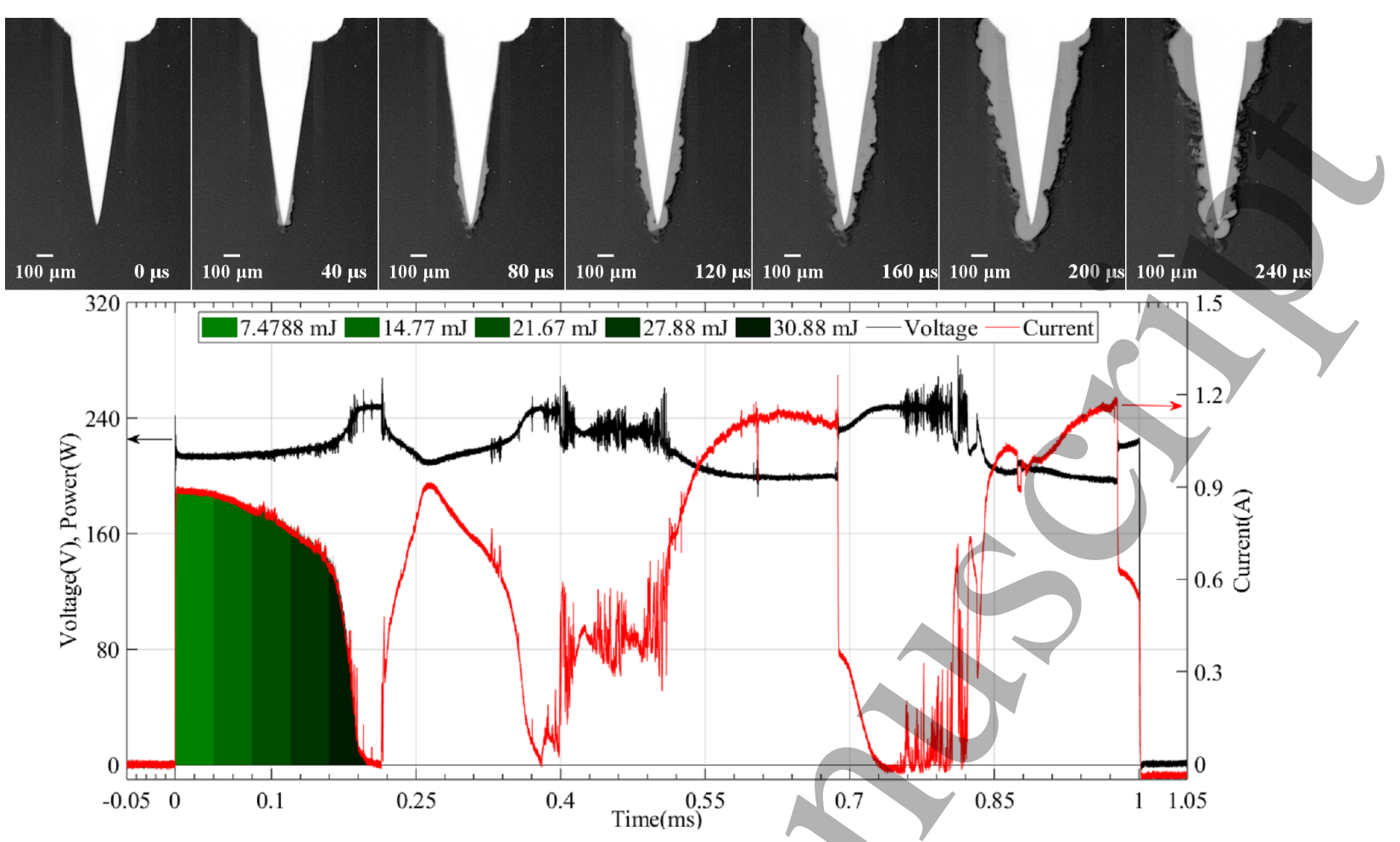


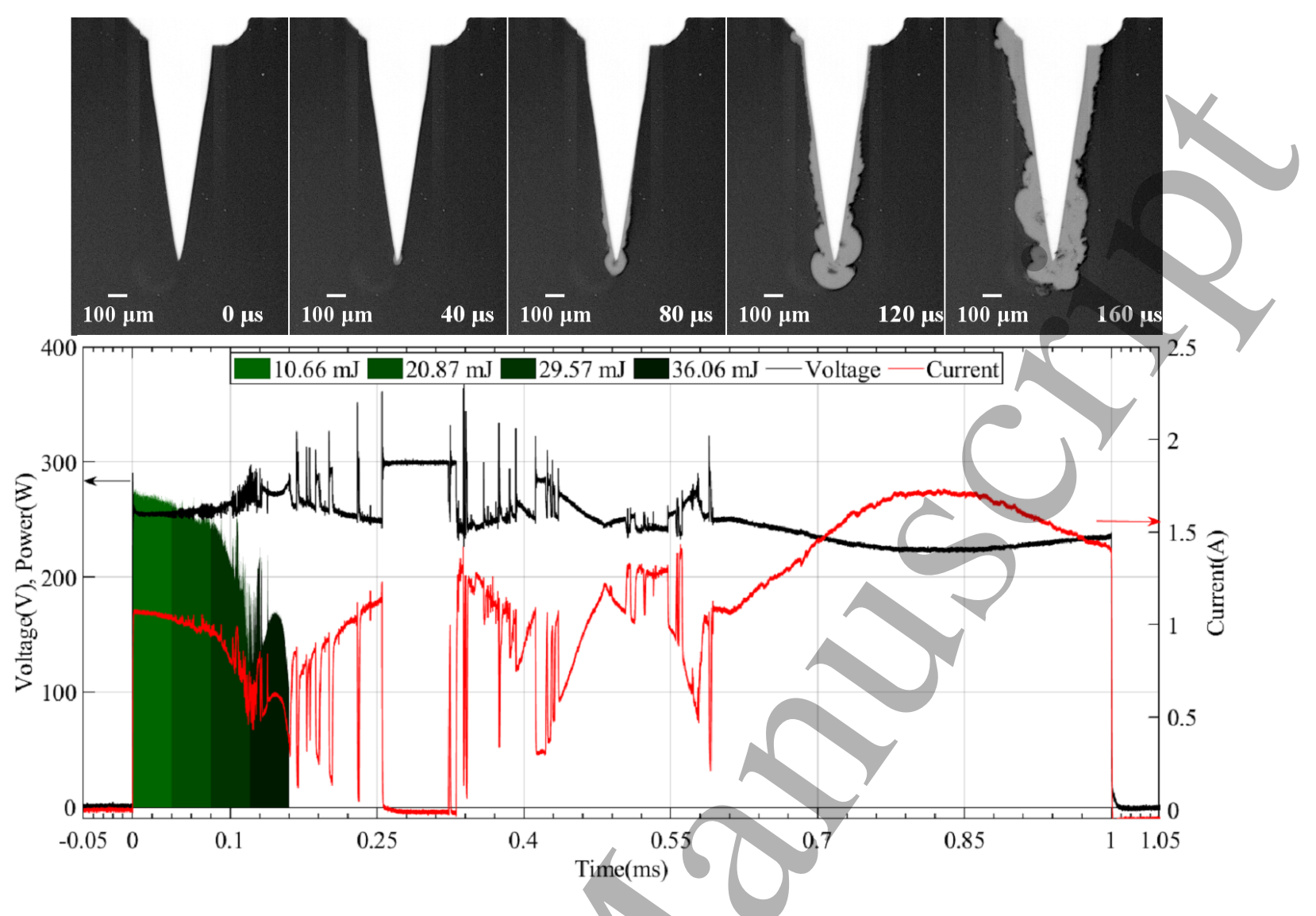

Figure 5. Time dependent shadowgraphy imaging and energy estimation per frame for $-300 \mathrm{~V}$ applied voltage. Fast faming images of the tip, vapour layer and liquid are shown along the top row at the times indicated. Below, electrical potential (black) on the powered electrode and current (red) are shown during the $1 \mathrm{~ms}$ voltage pulse. The line at the top of the green shaded area in the graph is power, the product of the voltage and the current. Both voltage $(\mathrm{V})$ and power $(\mathrm{W})$ values can be read from the left-hand axis scale. The green areas show the integration of power with time to determine energies; $E=\int_{0}^{t_{f}} V I d t$. For instance, the lightest green area starts from 0 $\mu \mathrm{s}$ to the time when the second frame was acquired at $t_{f}=40 \mu \mathrm{s}$ and the integrated energy in this window is $10.66 \mathrm{~mJ}$. The same procedure was repeated for each frame up to the frame at $160 \mu \mathrm{s}$ always integrating from $0 \mu \mathrm{s}$ up to the frame acquisition time. The different shades of green show the different limits of integration and are used in the key to identify the different energies obtained by integrating power.

and a diameter of $500 \mu \mathrm{m}$ and discharges were not observed before the current dropped to zero. As noted above, here a sharp tip with a radius of curvature of $\sim 500 \mathrm{~nm}$ at the end was used. The diameter of the widest part of the exposed tip was $\sim 330 \mu \mathrm{m}$.

From the electric field simulations, and the experimental results, it seems that for the data presented here the discharge is initially controlled by the fluctuations of the liquid and vapour boundaries. This can result in discharge formation before the current drops to zero.

The heights of the shaded area, shown along with the voltage and current traces in figures 2, 3, 4 and 5, represent the power dissipated between the powered electrode 


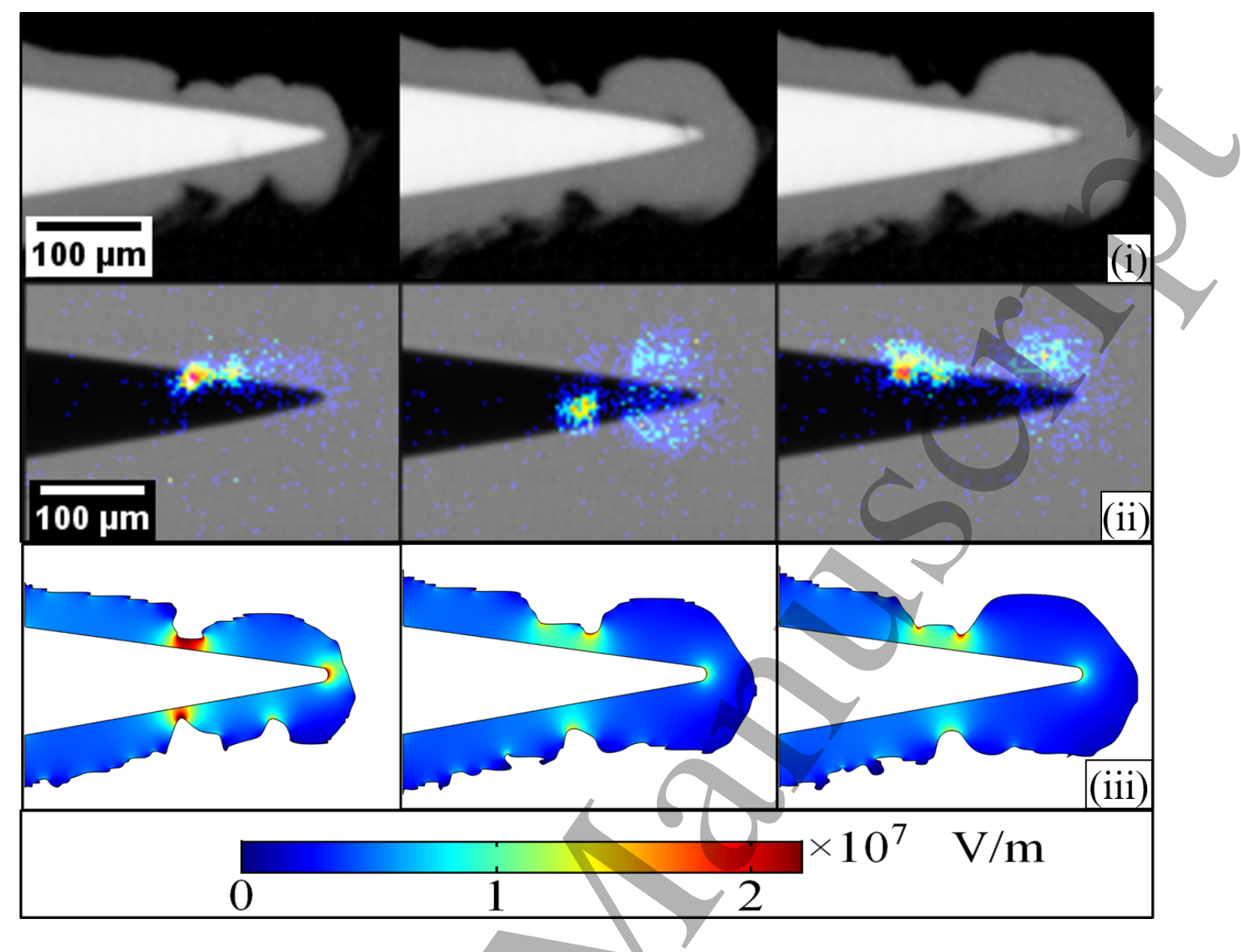

Figure 6. Images of $-250 \mathrm{~V}$ discharges acquired with a shutter of $1 \mu$ s and 400,000 fps with the FFC. The upper shadowgraphy images, (i), shows the vapour coverage around the bottom $\sim 300 \mu \mathrm{m}$ of the tip from a single shot. The three images in the middle, (ii), show discharge emission close to the tip at 155, 167.5 and $170 \mu \mathrm{s}$, which were all taken before the current dropped to zero. The images in (ii) were taken from a different shot without backlighting; the emission observed is shown with false colour to represent intensity superimposed above an image of the tip to show the location of the emission. Note that times of the frames in the shadowgraphy images (i) are the same as the times of the emission images shown in (ii). The bottom images, (iii), show electric field values calculated using the vapour liquid boundaries visible in the three shadowgraphy images shown in (i).

and the ground electrode, which is calculated by the product of the current and voltage. Thus, the shading represents the integration of power to calculate the energy dissipated in the system $[42,31]$. The total energy dissipated between the electrodes from the start of the pulse to the time of each image is also shown in figures 2, 3, 4 and 5 during the growth of the vapour layer. The electrical energy delivered prior to plasma breakdown drops with increasing voltage starting with $\sim 45 \mathrm{~mJ}$ for $-160 \mathrm{~V}, \sim 37 \mathrm{~mJ}$ for $-200 \mathrm{~V}$ and $\sim 30 \mathrm{~mJ}$ for $-250 \mathrm{~V}$. For $-300 \mathrm{~V}$ the energy is about $\sim 30 \mathrm{~mJ}$ close to that of $-250 \mathrm{~V}$. At $-300 \mathrm{~V}$, however, the energy is dissipated over a shorter time and so the power is higher at $-300 \mathrm{~V}$. 
It should be clarified here that 'current drops to zero' refers to the amplitude of the negative polarity current which decreases to a low value. For the cases of $-160 \mathrm{~V}$, $-200 \mathrm{~V}$ and $-250 \mathrm{~V}$ this refers to a decrease of more than $87 \%$. For the case of $-300 \mathrm{~V}$, however, the current does not drop below $67 \%$ of the initial value within the first 150 $\mu \mathrm{s}$ as a result of electrical discharges.

Time zero in the figures indicate the moment that the voltage was applied to the powered electrode. At time zero no micro-bubbles were observed around the tip. The last frame in figures 2, 3 and 4 of each case shows the vapour at the indicated time after the current dropped to close to zero.

For all the voltages, the images show the vapour layer becoming thicker around the electrode with time. The final images, however, for $-160,-200 \mathrm{~V}$ and $-250 \mathrm{~V}$ show vapour layers which are at least partially thinner than the previous frame. For example at -160 and $-200 \mathrm{~V}$ the vapour layer is significantly thinner around the sharp tip end in the final frame. In the final frame of $-250 \mathrm{~V}$ there is a region half way along the electrode where the liquid approaches the tip closely. These observations,suggest that the vapour layer collapses around the time when the current drops to zero and the voltage increases. The frame rate was not high enough to record exactly when the vapour layer starts to collapse; the time between frames was $40 \mu \mathrm{s}$.

\subsection{Boiling regimes predicted based on the boiling curve of water}

As described in section 2, a large quartz vessel and a low $1 \mathrm{~Hz}$ frequency with $1 \mathrm{~ms}$ pulses were used during this set of measurements. This was done to ensure that the temperature of the liquid does not significantly change from one pulse to the next. The prepared saline solution was not degassed and was exposed to ambient air throughout the experimental procedure. For this reason, nano-bubbles, which may persist from hours to weeks in a liquid sample, were most likely present in the solution [10]. The high reproducibility from shot to shot we observed, however, suggests that in the current experimental setup such nano-bubbles did not play an important role in discharge formation.

Figure 7 shows two images taken during the growth of the vapour layer; images are shown for -160 and $-300 \mathrm{~V}$. There is a clear difference between the shapes of the interface between the liquid and vapour layers in these two images. At $-160 \mathrm{~V}$ the vapour layer seems to be made up of many micro-bubbles which are coalescing, whereas at $-300 \mathrm{~V}$ the edge of the vapour layer is smoother. The observed differences in the vapour layers are most likely due to different boiling mechanisms.

It is well established that water boils with different mechanisms when it is in contact with a hot surface from pool boiling experiments [43]. When the temperature is about $5-30{ }^{\circ} \mathrm{C}$ above the boiling point, vapour is formed in small bubbles at the solid liquid interface in the 'nucleate boiling' regime. When the surface is at significantly higher temperatures above boiling, higher by $120{ }^{\circ} \mathrm{C}$ or more, a different boiling mechanism, 'film boiling', is observed where a film of vapour grows at the liquid-solid interface. It seems from the images in figure 7 that at the lower voltage nucleate boiling is observed 
and at the higher voltage film boiling is observed.
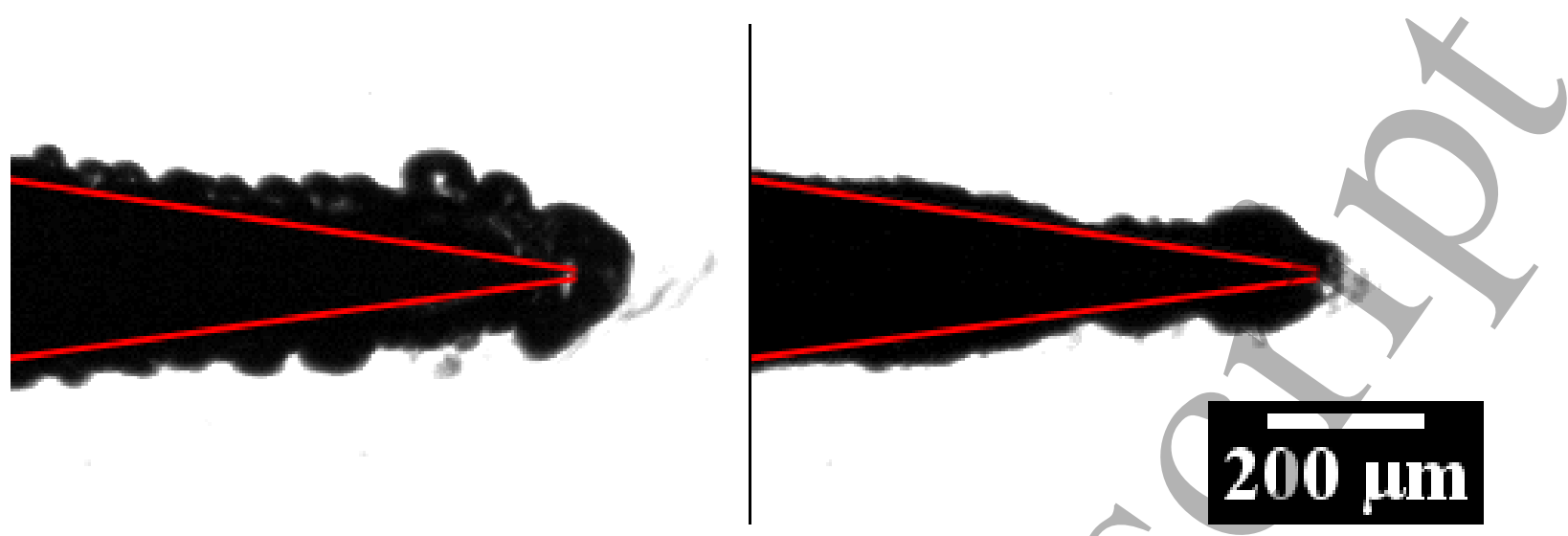

Figure 7. Two different shadowgraphy images are presented from two different shots. The left-hand image was recorded with a $-160 \mathrm{~V}$ pulse at $280 \mu$ s and the right-hand image was recorded with a $-300 \mathrm{~V}$ pulse at $80 \mu$ s. These images show examples of different boiling regimes of water; on the left, nucleate boiling where the vapour layer appears to be made up by the coalescence of many bubbles, and on the right at -300 $\mathrm{V}$ film boiling. The position of the tip is indicated with/red lines. These two images were acquired as part of series of images collected with a frame rate of 100,000 fps.

There is a fundamental difference, however, between vapour formation in the present study and boiling from a heated surface which has been studied previously [43]. With a heated surface all the heat that boils the liquid is transferred from the surface to the liquid. By contrast, in the present investigation, heat is generated by the flow of current through the liquid by Joule heating. This difference poses an obstacle to quantitative comparison between the present observations and results of pool boiling experiments; it is not obvious how to convert the heating power delivered here per unit volume to the equivalent heating power per unit area from heated surface experiments. Furthermore, there is hysteresis between the different boiling regimes so that the threshold power density between the two mechanisms varies between $10^{4}$ and $10^{6} \mathrm{~W} / \mathrm{m}^{2}$ for the transition from film boiling to nucleate boiling, and the transition from nucleate boiling to film boiling respectively [44].

A transition region between nucleate and film boiling has been observed in pool boiling experiments; this 'unstable film boiling regime' can be hard to obtain in practice. From the shape of the vapour layer growth at -200 and $-250 \mathrm{~V}$ observed here in figures 3 and 4 it may be that this transition boiling regime occurs here for these intermediate voltages.

The present results can, however, be compared with liquid discharge experiments where different boiling mechanisms have been observed, but these are all experiments with either continuously powered electrodes or experiments with significantly longer voltage pulses.

Korolev et al. have performed a similar experiment with negative $\mathrm{kHz}$ square wave and negative only square pulses applied to a cylindrical electrode in saline [45]. They 
observed bubbles rising to the free surface at low applied voltages $(100 \mathrm{~V})$, but state that at higher voltages these bubbles merged with each other to form thin film layers.

Yoon et al [32], have made a careful investigation of vapour layer formation with a powered electrode driven by an RF voltage and proposed a model. They have observed nucleate and film boiling mechanisms of the vapour formation. The model predicts that the surface of their electrode heats to above $300{ }^{\circ} \mathrm{C}$ leading to film boiling. Yoon et al., however, applied (380 kHZ) RF frequencies to their electrode for $800 \mathrm{~ms}$ or more and predict their electrode remains at ambient temperatures for the first $100 \mathrm{~ms}$ or more after the application of the RF power [32]. Thus, there does not appear to be any contradiction with the present investigation where voltage pulses of $1 \mathrm{~ms}$ are used and the electrode surface does not heat at the beginning of the pulse.

Shadrin and Belkin described the boiling they observed in their plasma electrolysis experiment as 'solution film boiling, in which heat generation in the VGE (vapour gaseous envelope) occurs' [46]. Here Shadrin and Belkin are/describing the heating they observed after the formation of the vapour layer around their powered electrode. They point out that, as the vapour layer has the highest resistivity, power dissipation and heat generation are most significant in the vapour layer compared to the electrode and surrounding liquid.

Yerokhin et al. has reviewed plasma electrolysis experiments [47]. They describe the transition between nucleate boiling and film boiling occurring at a critical Joule heating power density, which is in agreement with the present observations of film boiling at higher voltage and, hence, higher Joule heating power density.

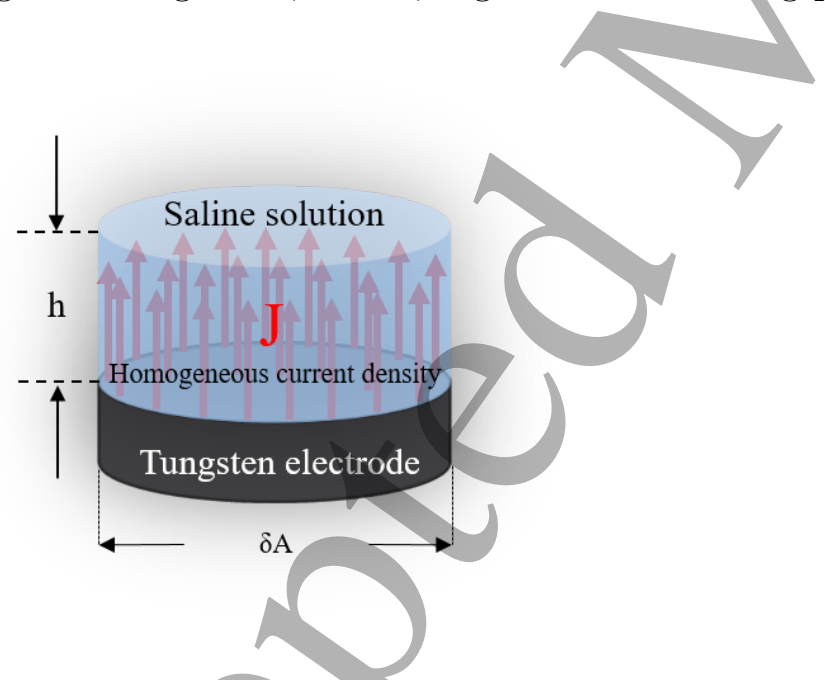

Figure 8. Simplistic model for the estimation of breakdown time after the application of the yoltage pulse.

\subsection{A simple model of prebreakdown vapour formation}

A simple prebreakdown vapour formation model has been developed to predict the time between the start of the voltage pulse and breakdown. The principle of the model is that prior to breakdown the liquid adjacent to the electrode is vaporized by Joule heating. 
Thus, to predict the time to breakdown, the model estimates the time taken to produce vapour adjacent to the electrode. The following assumptions are made in the model.

- The liquid can be modelled as shown in figure 8 with a cylindrical slab of cross sectional area $\delta A$ and height $h$ adjacent to the powered electrode.

- The current passing through the liquid adjacent to the electrode has uniform density and a direction of flow perpendicular to the surface of the electrode.

- Physical constants for the liquid are values for $0.9 \mathrm{~g} / \mathrm{l} \mathrm{NaCl}$ solution at 298.16 $\mathrm{K}$. It is assumed these values do not change with temperature. These values are; resistivity of the liquid $\rho=0.62 \Omega \mathrm{m}$, as measured with the conductivity meter, specific heat capacity $C_{p}=4131.63 \mathrm{~J} / \mathrm{kgK}[48]$, and density $D=1003.3 \mathrm{~kg} / \mathrm{m}^{3}$ [49].

- Initially, the liquid temperature is $298 \mathrm{~K}\left(25^{\circ} \mathrm{C}\right)$ and the liquid turns to vapour at $373 \mathrm{~K}\left(100^{\circ} \mathrm{C}\right)$ so the change in temperature $\Delta T=75 \mathrm{~K}$.

- The total initial current, $I$, measured from the experimental data remains constant prior to breakdown. This is a simplification as in reality the current is not constant and, for example, drops before breakdown. The current density is $I / A$ where $A$ is the exposed surface area of the powered electrode, $0.6 \mathrm{~mm}^{2}$.

For the liquid sample considered in figure 8 , the current flowing $\delta I$ is given by:

$$
\delta I=\frac{I}{A} \delta A
$$

and the resistance $\delta R$ is given by:

$$
\delta R=\frac{\rho h}{\delta A}
$$

so the heat energy, $q$, generated over time $t$ in the liquid sample is given by:

$$
q=t \delta I^{2} \delta R=t\left(\frac{I}{A}\right)^{2} \delta A \rho h
$$

The energy $\Delta U$ required to heat the liquid to boiling point is:

$$
\Delta U=C_{p} \Delta T \cdot \delta m=C_{p} \Delta T \cdot D h \delta A
$$

where $\delta m$ is the mass of the liquid; $\delta m=D h \delta A$.

By equating $q$ and $\Delta U$ in Equations 3 and 4 the time required to heat the liquid to boiling is given by:

$$
t=\frac{\Delta U \delta R}{\delta I^{2}}=\left(\frac{A}{I}\right)^{2} \frac{C_{p} D \Delta T}{\rho}
$$

Thus, the time to breakdown can be predicted with this model on the basis of the initial current observed, $I$, the exposed electrode area, $A$, the temperature rise $\Delta T$, and physical constants. In fact, the initial impedance of the path to earth from the powered electrode is found to remain constant to within $1 \%$ as the applied voltage was varied and so the initial current can be accurately estimated from the applied voltage and this impedance, which is $242 \pm 1.5 \Omega$ measured from the electrical signals. 
Table 1. Data summarized for the voltage pulses shown in figures 2, 3, 4 and 5 along with the times to breakdown predicted from the simple model. ${ }^{*}$ The values shown were acquired by fitting the data before $120 \mu \mathrm{s}$ with 7 th and 5 th degree polynomial which gave times of 128 and $137 \mu$ s, respectively.

\begin{tabular}{|c|c|c|c|}
\hline $\begin{array}{l}\text { Applied } \\
\text { Voltage } \\
(\mathrm{V})\end{array}$ & $\begin{array}{l}\text { Initial } \\
\text { Current } \\
(\mathrm{A})\end{array}$ & $\begin{array}{l}\text { Expt. } \\
\text { time to } \\
\text { vapour } \\
(\mu \mathrm{s})\end{array}$ & $\begin{array}{l}\text { Model } \\
\text { time to } \\
\text { vapour } \\
(\mu \mathrm{s})\end{array}$ \\
\hline-160 & $0.564 \pm 0.016$ & 738 & $570 \pm 50$ \\
\hline-200 & $0.695 \pm 0.014$ & 420 & $375 \pm 20$ \\
\hline-250 & $0.888 \pm 0.012$ & 214 & $230 \pm 10$ \\
\hline-300 & $1.066 \pm 0.013$ & $128,137^{*}$ & $160 \pm 5$ \\
\hline
\end{tabular}

The model does not take account of the latent heat of vaporization, $\Delta H_{v a p}$. The expansion of water on boiling at atmospheric pressure means that if about one thousandth of the water in the sample volume boils the water vapour formed will completely fill the sample volume at a pressure of/one atmosphere. The latent heat required to vaporize this small fraction of the liquid is equivalent to the energy required to heat all the liquid in the sample by less than $1 \mathrm{~K}$, so the latent heat of vaporization is insignificant compared to the energy required to heat the liquid $\ddagger$

Table 1 shows a comparison of the times observed experimentally to form a 'prebreakdown vapour layer' and the times calculated with this simple model. These data are also shown in figure 9. The results are in reasonable agreement given simplicity of the model and that the model has no adjustable parameters. Note that the experimental time to prebreakdown vapour layer formation is estimated from the time between the start of the pulse to the time at which the current drops to zero or close to zero. As described in section 3.1, for $-300 \mathrm{~V}$ the current does not fully drop to zero before significant electrical discharge. Thus, for the case of $-300 \mathrm{~V}$ the value of the time that the current would have dropped to zero as a result of Joule heating, is estimated by extrapolation for the current trace before $120 \mu$ s to zero. After $120 \mu \mathrm{s}$, there is an obvious drop of the ionic current component but the contribution of discrete plasma pulses to the current prevent the current from dropping to zero.

Clearly, this simple crude model does not incorporate many physical processes during the boiling mechanism, but it is presented here because the calculation is straight forward and it, perhaps surprisingly, provides good estimates of experimental

$\ddagger$ A mass, $m_{l} \mathrm{~kg}$, of liquid water occupies a volume, $V=\sim m_{l} / 1000 \mathrm{~m}^{3}$. From the ideal gas law, $n$, the number of moles of gas with the same volume, $V$, at $100{ }^{\circ} \mathrm{C}$ and one atmosphere pressure is given by $n=P V / R T=\left(1 \times 10^{5} m_{l} / 1000\right) /(8.314 \times 373)=0.032 m_{l}$. The mass of $n$ moles of gaseous water, $m_{g}$ is given by $m_{g}=0.018 n=0.0006 m_{l}$. The latent heat of vapourization is $2260 \mathrm{~kJ} / \mathrm{kg}$ and the specific heat capacity of water is $4.2 \mathrm{~kJ} / \mathrm{kgK}$. So the latent heat required to vapourize 0.0006 of a liquid sample is $\sim 1.4 \mathrm{~kJ} / \mathrm{kg}$, which is equivalent to raising the temperature of the full sample by $1.4 / 4.2 \mathrm{~K}=\sim 0.3$ $\mathrm{K}$ and, thus, less than $1{ }^{\circ} \mathrm{C}$. 


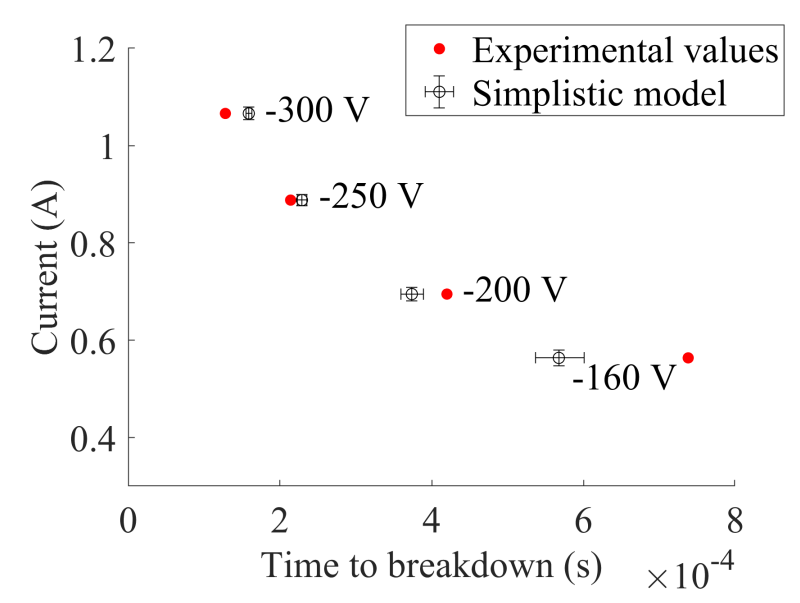

Figure 9. Comparison and experimentally measured and calculated times to breakdown. The calculate times were determined with the simple model of time to vapour coverage of the tip.

vapour layer formation times. It may, therefore, provide a useful 'rule of thumb' for calculation of the time for formation of prebreakdown vapour layers in conducting liquids. Troughton et al. have used a similar approximation to estimate the energy consumption for the various processes that they observed in their experiment [17]. Another example of a similar calculation has been made by Palanker et al. who derived expressions for the time to vapour formation and the energy deposited [50].

One final point here is that the Joule heating of the surface of the tungsten carbide tip can be estimated by a similar calculation. Tungsten has a resistivity of $5.427 \times 10^{-8}$ $\Omega \mathrm{m}[51,52]$, specific heat capacity of $131.29 \mathrm{~J} /(\mathrm{kg} \mathrm{K})[52]$ and a density of $19.25 \times$ $10^{3} \mathrm{~kg} / \mathrm{m}^{3}$ [52]. With these values it is found that the rate of Joule heating of the surface of a tungsten electrode is about seven orders of magnitude slower than the rate of Joule heating of the adjacent saline, which is due to the resistivity of tungsten being about $10^{7}$ times smaller than the resistivity of saline. Tungsten carbide has a resistivity of $\sim 2 \times 10^{-7} \Omega \mathrm{m}$ and so similarly the Joule heating of tungsten carbide will be insignificant comparted to the heating of the liquid.

This model predicts faster vaporization rates for higher currents, and hence higher voltages, and for smaller exposed electrode areas.

In this simplistic model, a two phase system of tungsten electrode in contact with liquid was considered. Yerokhin et al has proposed a four phase system to account for the formation of a dielectric layer and the vapour layer during a plasma electrolysis experiment $[47]$

3.4. Analysis of the 'prebreakdown vapour' electrical conductivity with an improved model

The nature of the 'prebreakdown' vapour layer observed in the fast framing images is not well understood. For example, Shadrin and Belkin [46] have estimated 
an average electrical conductivity of $2.13 \times 10^{-3} \mathrm{~S} / \mathrm{m}$ for a 'vapour gas envelope' between a continuously running powered anode and ammonium nitrate solutions with concentrations of 1 to $3 \mathrm{~mol} / \mathrm{l}$. By contrast Schaper et al [38] estimated a conductivity of $\sim 3.2 \times 10^{-10} \mathrm{~S} / \mathrm{m}$ for water vapour above saline solution at $100.15{ }^{\circ} \mathrm{C}$.

Here, the simultaneously collected electrical data and images from the fast framing camera have been used to estimate the conductivity of the vapour layer. The fast framing camera images have been processed to generate images showing regions of liquid, vapour and electrode. The procedure is outlined in Appendix A and images of this procedure are shown in figure A1.

The processed images are considered to be two dimensional slices through the centre of the electrode, vapour bubble and liquid. If cylindrical symmetry is assumed then slices can be rotated about the vertical axis of the electrode to generate the 3D structure of the vapour and liquid close to the electrode. Of course, each side of the $2 \mathrm{D}$ image can be rotated separately to generate two different 3D maps.

The assumptions made to analyse the 3D maps obtained from the images are:

- Cylindrical symmetry

- Uniformity of the liquid and vapour layers. The conductivity of the liquid layers is $1.61 \mathrm{~S} / \mathrm{m}$. The conductivity of the vapour layer is uniform.

- The remaining volume of the bulk liquid not visible in the images taken by the fast framing camera, is modelled with a single 'external' resistor between the lower plane and the vertical sides of the liquid and earth, which does not change during the application of the voltage pulse.

With these assumptions COMSOL Multiphysics ${ }^{\circledR}$ modelling software [41] has been used to calculate the effective conductivity of the vapour layer. The value of the external resistance required between the outer edges of the liquid layer and earth was found by modelling the impedance of the system at time zero when there are no bubbles or vapour layers attached to the electrode and the total electrical impedance of the liquid is experimentally determined. This way, the additional resistance that has to be added to the geometry in order to match the experimental value is determined. As mentioned earlier, the total initial impedance of the liquid is $242 \pm 1.5 \Omega$ and the value for the external resistor for the model geometry is calculated to be $55 \pm 1.5 \Omega$.

The conductivity of the vapour layer in each image frame is calculated with COMSOL by importing the 3D map of the electrode, vapour layer and liquid layer. Different trial vapour conductivity values are tested until the total impedance predicted by COMSOL, including the external resistance, matches the experimentally observed impedance at the time when the image frame was acquired. This process is carried out twice for each frame; once using the 3D map generated from the left-hand side of the image and once using the right-hand side of the image.

Figure 10 shows the variation of the calculated vapour conductivity with time. Results are shown for $-160 \mathrm{~V},-200 \mathrm{~V},-250 \mathrm{~V}$ and $-300 \mathrm{~V}$. For the majority of the frame images that were acquired it is possible to calculate the conductivity of the vapour from 


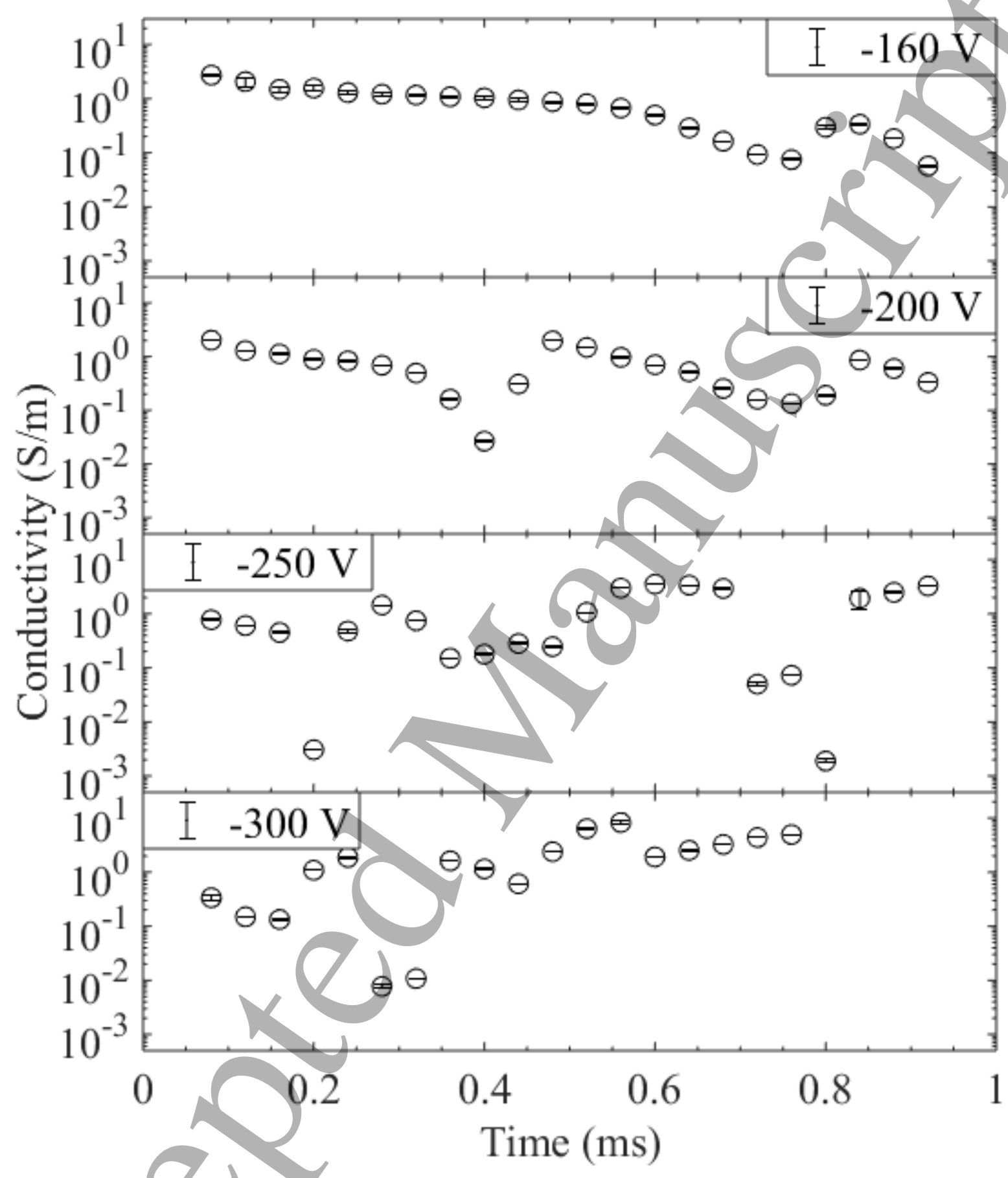

Figure 10. Vapour layer conductivity values presented for the four different applied voltages investigated here.

the left and right sides of the image; in these cases, error bars are drawn between the two calculated values. The errorbars, however, are often so small that it is difficult to distinguish them from isolated points. 
For some frames, particularly when the vapour thickness is comparable to the resolution of the optical setup, it is not possible to resolve well the boundaries of the vapour. For this reason, it has not been possible to calculate conductivities at $40 \mu \mathrm{s}$ and the first values shown for all voltages are at $80 \mu \mathrm{s}$. Similarly, at -300 V the calculation of vapour conductivity for frames after $800 \mu$ s has not been possible because in these frames the vapour bubble had expanded outside the image frame of the camera and thus the liquid vapour boundary could not be determined.

The initial conductivity of the vapour is high, almost as high as the liquid saline solution, which as noted above is $1.6 \mathrm{~S} / \mathrm{m}$. As the vapour layer grows the conductivity of the vapour drops slowly. At some point the calculated conductivity drops more rapidly which corresponds to the time when the current drops to close to zero just before the plasma discharge is initiated.

The high values of conductivity calculated here for the vapour layer are surprising considering that normally water vapour at the boiling point of saline would be expected to have a conductivity of $\sim 3.2 \times 10^{-10} \mathrm{~S} / \mathrm{m}$ [38]. Furthenmore, it is worth considering that the model used to enable these calculations assumes the vapour layer is uniform; if it is not uniform then some areas of the vapour must have higher conductivities than the values reported here. It is striking, however, that the average conductivity estimated by Shadrin et al. for their gaseous vapour envelope, $2.13 \times 10^{-3} \mathrm{~S} / \mathrm{m}$ [46], is at the lower limit of the conductivities determined here. For example, at $200 \mu \mathrm{s}$ for the $-250 \mathrm{~V}$ case the model predicts a value of $3.3 \times 10^{-3} \mathrm{~S} / \mathrm{m}$.

The anomalously high vapour conductivity could be due to injection of charge carriers into the vapour by corona discharge at the sharp tip of the electrode. Alternatively, ions from the liquid saline solution might be present in the vapour layer. Finally, the vapour layer could consist of a 'foam' mixture of low conductivity vapour bubbles separated by thin high conductivity layers of liquid. These different alternatives are considered below, but note that at this time there is no clear conclusion about which of these mechanisms makes the largest contribution to the vapour layer conductivity and the reason for the observation of these high vapour layer conductivity will require further investigation.

Corona discharge at the sharp tip of the electrode is a possible source of charge carriers in the vapour layer because of the high electric fields predicted near the end of tip. In section 3.5 below the electric field strength is estimated to be greater than $10^{7}$ $\mathrm{V} / \mathrm{m}$ close to the sharp tip of the electrode, but it is predicted to drop rapidly to below $10^{5} \mathrm{~V} / \mathrm{m}$ at the vapour liquid interface. This type of electric field profile is typical for corona discharges; very high electric field strength by one electrode where the discharge occurs, but the electric field is orders of magnitude weaker at the counter electrode, which is usually at earth or ground potential. The weakness of the electric field at the counter electrode means that the discharge is confined to the high electric field strength region. This electric field profile from the sharp point of the tip through the vapour layer to the vapour liquid interface is seen consistently in the majority of frames taken during the voltage pulse. Finally, some weak emissions is observed surrounding the sharp tip 
of the electrode in figure 6 which could be due to Corona discharge.

The ejection of ions from the bulk liquid into the vapour phase seems unlikely, but sodium emission is consistently observed in spectra of plasma emission from saline solutions. Bruggeman et al [53, 54] conducted experiments in a capillary type of discharge in saline solutions with self-generated vapour bubbles and air bubbles. In their optical emission spectra sodium emission is absent for the case of the air bubble, but intense sodium emission lines at $589 \mathrm{~nm}$ are observed for the vapour bubble generated by Joule heating. They point out that 'a large evaporation rate is necessary to observe strong sodium emission of the plasma', which implies that sodium ions from the liquid reach the vapour. Further evidence was presented by Xiong et al. who found that the emission intensity of sodium lines depended on the concentration of sodium in the surrounding liquid [55]. The sodium ions would most likely pass from the liquid to vapour as hydrated cluster ions. Hydrated chloride ions could also be present in the vapour phase, but, in contrast to the case of sodium, no clear spectroscopic evidence for the presence of chlorine in the vapour layer has been found in the literature.

The third possible explanation for the high observed conductivity in the vapour layer is that the vapour consists of a 'foam-like' mixture of bubbles and saline. The vapour could have the expected low conductivity and the high conductivity would be due to saline channels between the bubbles.

The reason is not clear for the large deviations between the conductivity of pure water steam and that of the vapour layer observed here, which is generated as a result of Joule heating in a saline solution. Possible explanations are currently being investigated.

\subsection{Electric field and breakdown with the improved model}

The finite element simulation was used to estimate the electrical potential in the vapour region for each fast framing image by applying the experimentally measured potential to the electrode and using the calculated effective conductivity of the vapour layer. The electric field was determined from the electrical potential; full details of the procedure are given in Appendix A.

Figure 11 shows a typical example of a map of the electric field strength calculated in the vapour layer region for the case of $-300 \mathrm{~V}$ and $280 \mu \mathrm{s}$. The colour bar beside the image indicates the electric field strength, which is, of course, the magnitude of the electric field. The electric field strengths in the vapour region along the three lines shown in figure 11 are presented in figure 12 as a function of the percentage distance along the line between the electrode and vapour liquid interface. Two lines are drawn from the sharp tip of the electrode through the vapour layer to the liquid; one is horizontal (green) and one is vertical (red). The third line (black) is drawn horizontally from the side of the electron to position of the liquid vapour interface which is closest to the electrode.

It can be seen in figure 12 that the electric field strength is highest close to the sharp tip of the electrode with values above $10^{7} \mathrm{~V} / \mathrm{m}$ visible for both the vertical and 


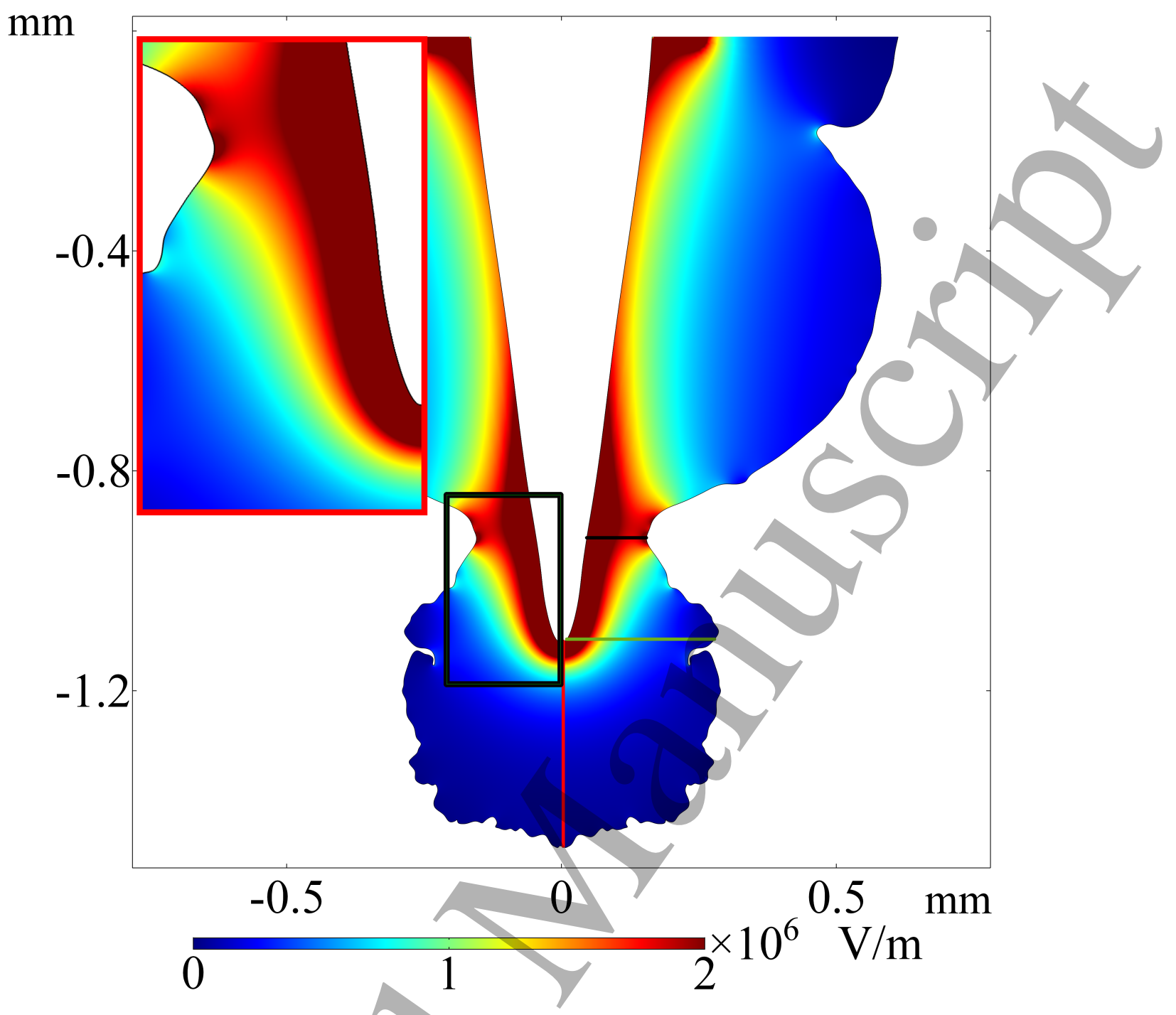

Figure 11. Electric field map calculated for the case of $-300 \mathrm{~V}$ and $280 \mu$ s delay from the initiation of the voltage application. The value of the calculated conductivity as given in figure was used for the simulation. The black box indicates the magnified region shown in the same figure.

horizontal lines close to the sharp point of the electrode. The electric field strength along these two lines from the sharp tip, however, drops to $\sim 10^{5} \mathrm{~V} / \mathrm{m}$ at the liquid vapour interface. The electric field is more constant along the third line between the electrode and the closest point of the liquid to the electrode; in this region it remains between $\sim 1.5 \times 10^{6}$ and $4 \times 10^{6} \mathrm{~V} / \mathrm{m}$.

Yerokhin et al. reported in a plasma electrolysis experiment that electric fields of the order of $10^{6}$ to $10^{8} \mathrm{~V} / \mathrm{m}$ were present in their gaseous envelopes, which are close to the electric field strengths observed here.

The liquid vapour interface in figure 11 appears to show that there are two vapour bubbles around the electrode; one bubble is centred on the end of the electrode and the other is higher up the electrode. Where the two bubbles meet the saline and vapour 


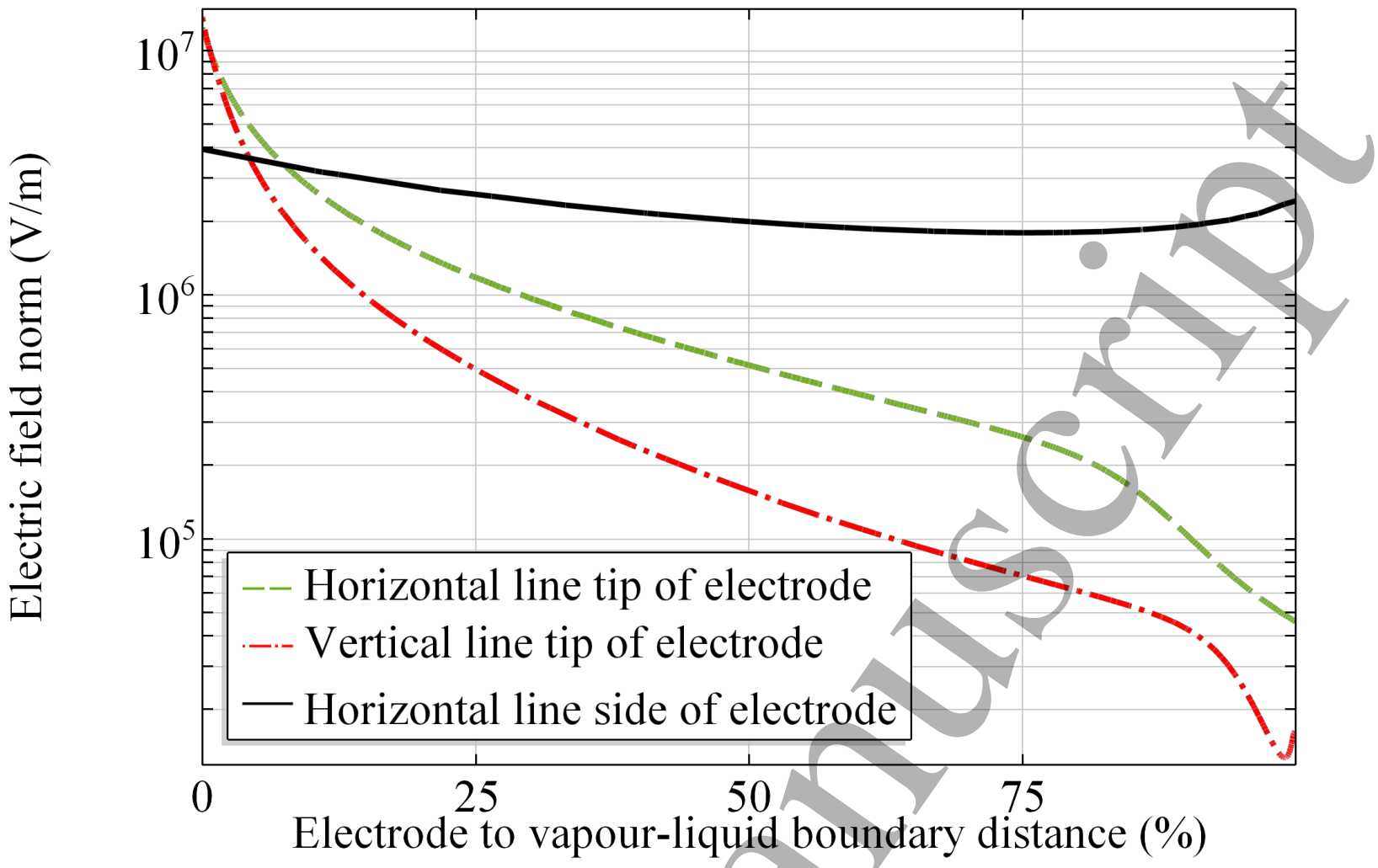

Figure 12. Electric field values across the lines indicated with the same colours in figure 11 .

interface is closest to the electrode and 'points in' towards the electrode, which helps to maintain the high electric field between the electrode and liquid vapour interface in this region.

Initial conclusions from this and other similar calculations of the electric field in the vapour layer around the electrode are that a corona discharge may be formed in the highest electric field region close to the tip, but this discharge does not reach the vapour liquid interface where the electric field is orders of magnitude lower. By contrast, between the side of the electrode and the saline vapour interface the continuously high electric field could initiate and sustain a plasma between the electrode and liquid vapour interface.

Experimentally, plasma emission is mostly observed from the vapour layer closest to the side of the tip, which is expected from the calculated electric field in the vapour region. For example, in figure 6 (ii) above the strongest emission is observed at the side of the electrode. Some weaker emission is visible close to the tip of the electrode in figure 6 , which may be due to a corona discharge near the sharp end of the electrode.

Further evidence for the significant plasma discharge near the side of the electrode is visible in the SEM images of the tip before and after the experiments shown in figure 13 and figure 14, respectively. There is localised erosion on the side of the electrode as well as erosion to the sharp end of the tip. The tip was used for a total of 172 pulses of 

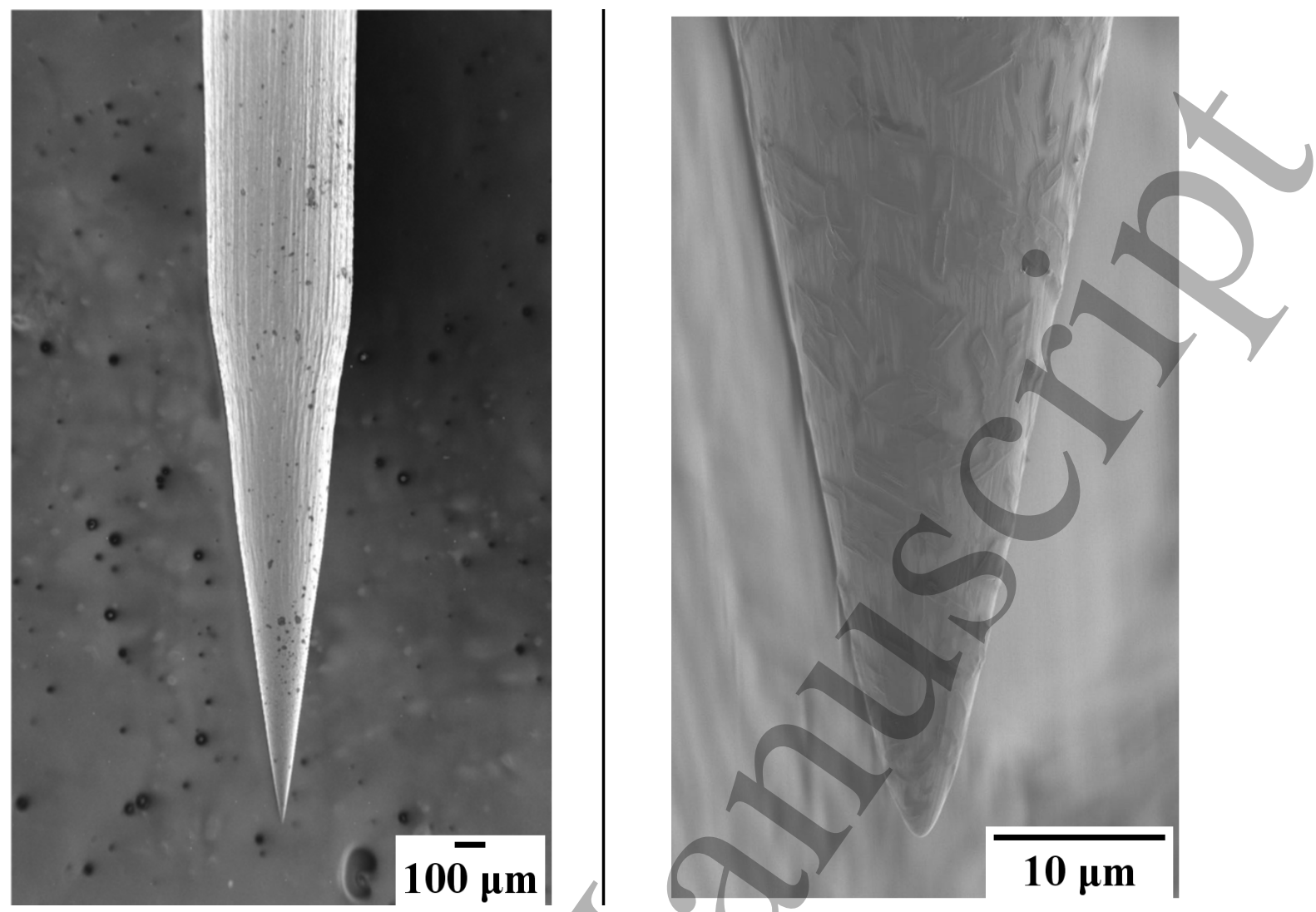

Figure 13. Scanning electron microscopy image showing the tip profile and surface before it was used for production of discharges in liquids.

time-on ranging from 1 to $10 \mathrm{~ms}$, in saline solutions of $0.9,1.8$ and $2.7 \%$ concentrations at nominal voltages of -140 to $-300 \mathrm{~V}$.

Sie et al. have investigated the effect of erosion on a tungsten powered electron in saline [56]. They note that for positive electrode bias electrolytic oxidation leads to damage of the tungsten, but above $+150 \mathrm{~V}$ damage from the plasma is more important than electrolytic oxidation. They note that for negative electrode bias, as in the present experiments, no electrolytic oxidation is observed, but again damage is seen from plasma erosion and thermal effects. Here, the erosion of the tip comes most likely from 'long lived' discharges that persist for 100 s of $\mu$ s such as the discharge observed after $590 \mu \mathrm{s}$ at $-300 \mathrm{~V}$ seen in current and voltage signals of figure 5 .

A series of images taken of a long lived discharge with the fast framing camera are shown in figure 15. The discharge wanders slowly around the tip as the bubble expands causing sputtering. The crater visible on the right-hand side of the electrode in figure 14 is probably formed by ion bombardment from the adjacent plasma and heating of the surface by the plasma $[56,57]$. Video supplementary material is available online, which shows the development of discharge emission with time for the first millisecond of the pulse along with the measured voltage and current.

The discharges start mostly on the side of the electrode because of the shape of the 

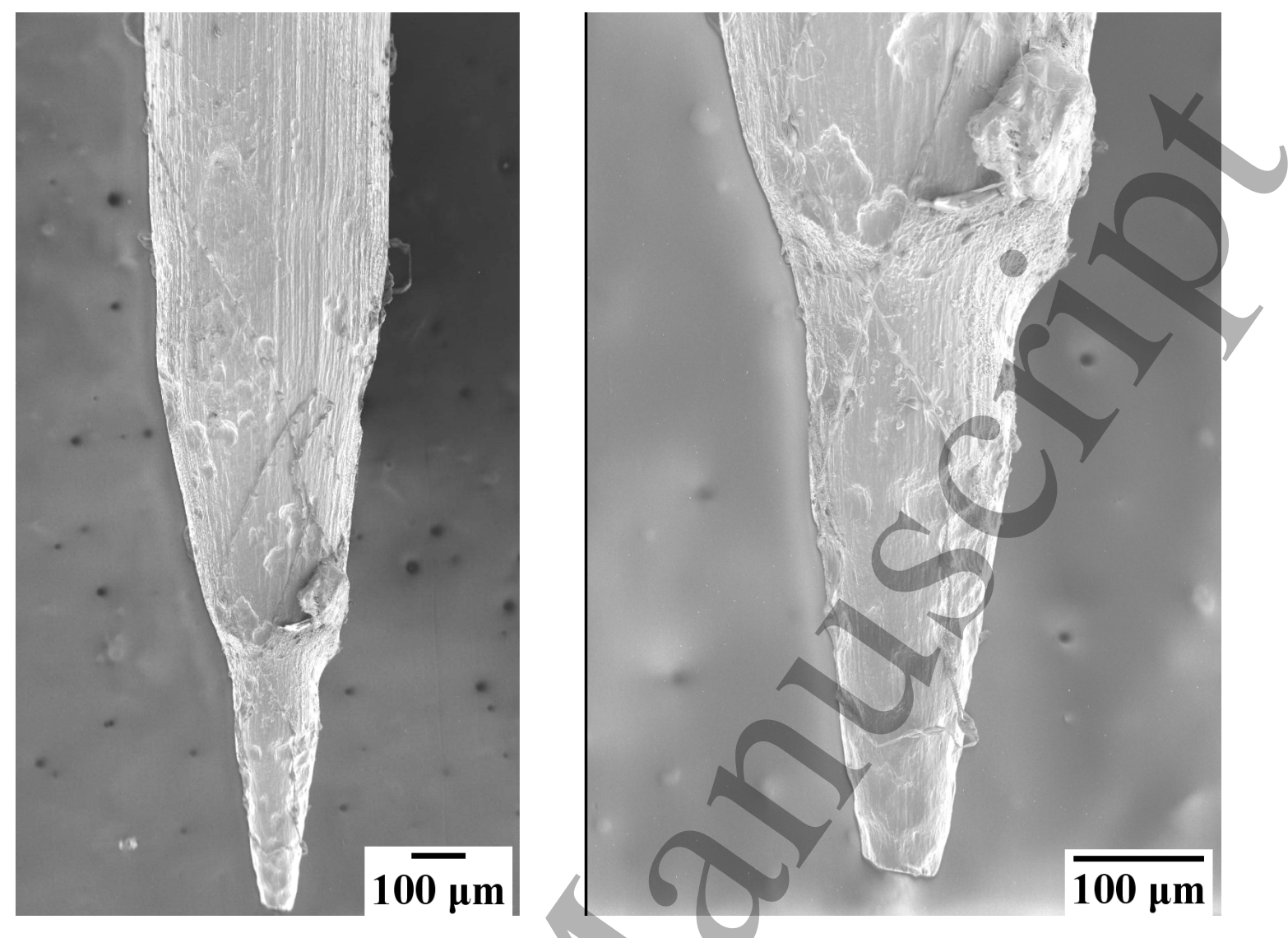

Figure 14. Scanning electron microscopy image of the tip after the end of experiments.

liquid-vapour interface, but after time the liquid-vapour interface moves further away from the location of the electrode. The movement of the liquid-vapour interface changes the electric field distribution in the vapour region, but the discharge remains in a similar location on the side of the electrode as can be seen in figure 15. The discharge can be sustained by two mechanisms after the electric field changes. First, ion bombardment of the electrode will release electrons to sustain the discharge. Secondly, heating of the electrode by ion bombardment may raise the temperature of the electrode high enough for it to release electrons by thermionic emission.

\subsection{Derivation of plasma electron density based on bubble conductivity and electric field calculations}

In figure 16 the values of the conductivities estimated with the improved model are plotted against the volume of the vapour layer. The volume of the vapour layer was calculated from each frame taken with the fast framing camera. The vapour liquid interface was identified as described in refsec:appendix1. The volume was calculated by assuming cylindrical symmetry and rotating the liquid vapour interface around the vertical axis. The volume was calculated twice for each frame; once by using the vapour liquid interface on the left-hand side of the electrode and the other time by using the 


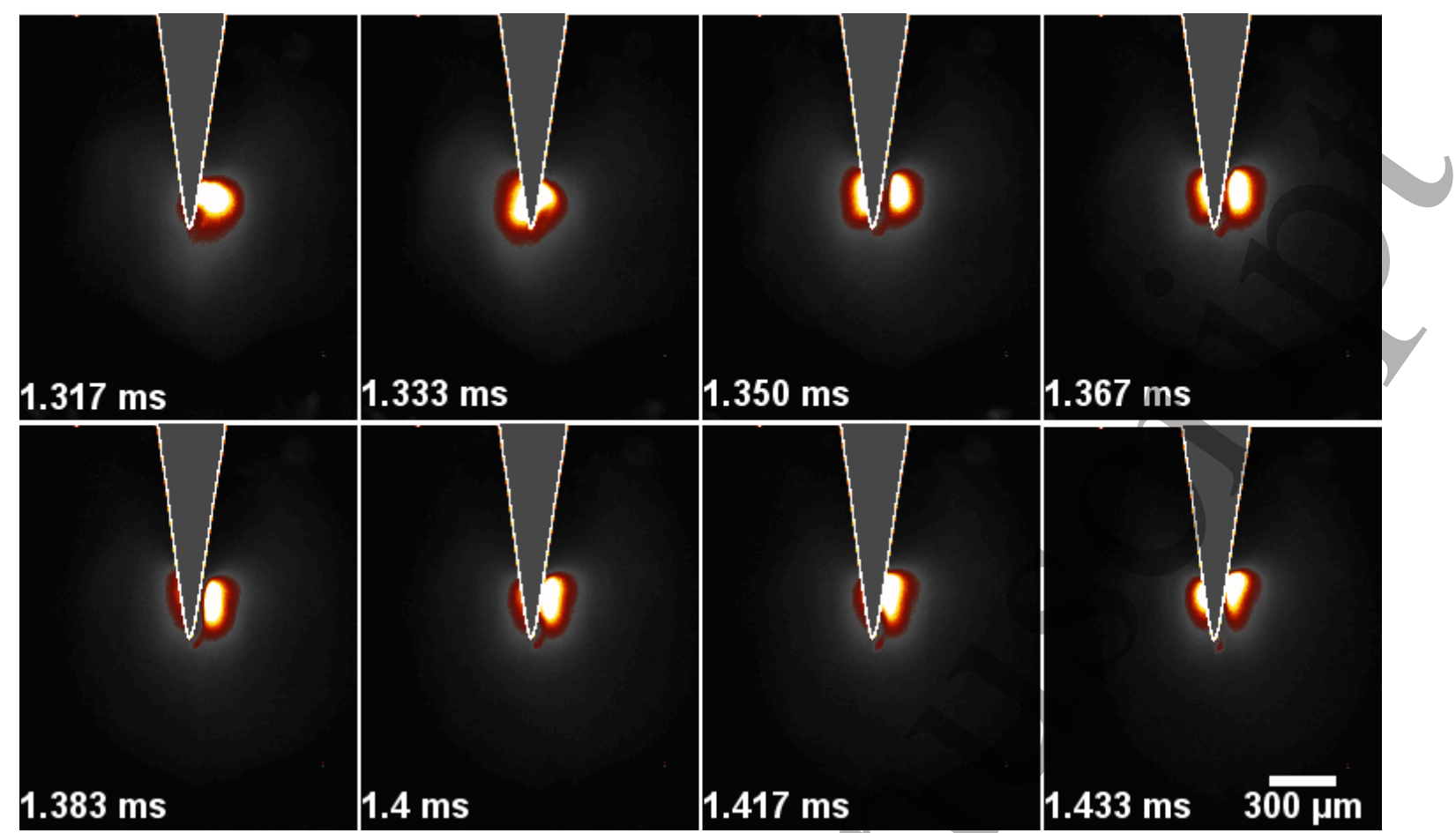

Figure 15. A series of consecutive images from the fast framing camera showing discharge emission near the location of the crater seen in the SEM images. The discharge was produced in a $2.7 \%$ saline solution with a $5 \mathrm{~ms}$ duration $-200 \mathrm{~V}$ voltage pulse. The times indicated on each image are the times each frame was taken after the start of the voltage pulse. The emission images are superimposed over an image of the tip with a white line indicating the edge of the tip.

vapour liquid interface on the right-hand side of the electrode. The average of these two values of the vapour volume is plotted on figure 16 and for each point a horizontal error bar is drawn from the higher measurement of the vapour volume to the lower measurement. There are some points, particularly at low volumes, where these error bars are so short that it is not possible to see them.

It is clear from figure 16 that at the lower voltages of -160 and $-200 \mathrm{~V}$ the maximum vapour volume is $\sim 0.4 \mathrm{~mm}^{3}$. At $-160 \mathrm{~V}$ there is a clear correlation between conductivity and vapour volume, with the conductivity decreasing as the volume increases. At -200 $\mathrm{V}$ the same trend is observed as at $-160 \mathrm{~V}$, but between $\sim 0.1$ and $0.4 \mathrm{~mm}^{3}$ a cluster of points lie above this trendline with somewhat higher conductivities. With pulses of -250 and $-300 \mathrm{~V}$ some points follow the same trend as the points at $-160 \mathrm{~V}$, but a significant group of points have conductivities of over $1 \mathrm{~S} / \mathrm{m}$ and higher volumes from $0.1 \mathrm{~mm}^{3}$ to over $1 \mathrm{~mm}^{3}$. These points with high conductivity and high volume occur when an electrical discharge is present. Note that generally the discharge is located in a small region of the vapour layer, which can lead to quite asymmetric development of the vapour region. The asymmetry is observed in the shadowgraphy images as, for example, the discharge may cause one side of the vapour layer to grow more than the other. This asymmetry can cause significant differences in the vapour volume calculations from the 


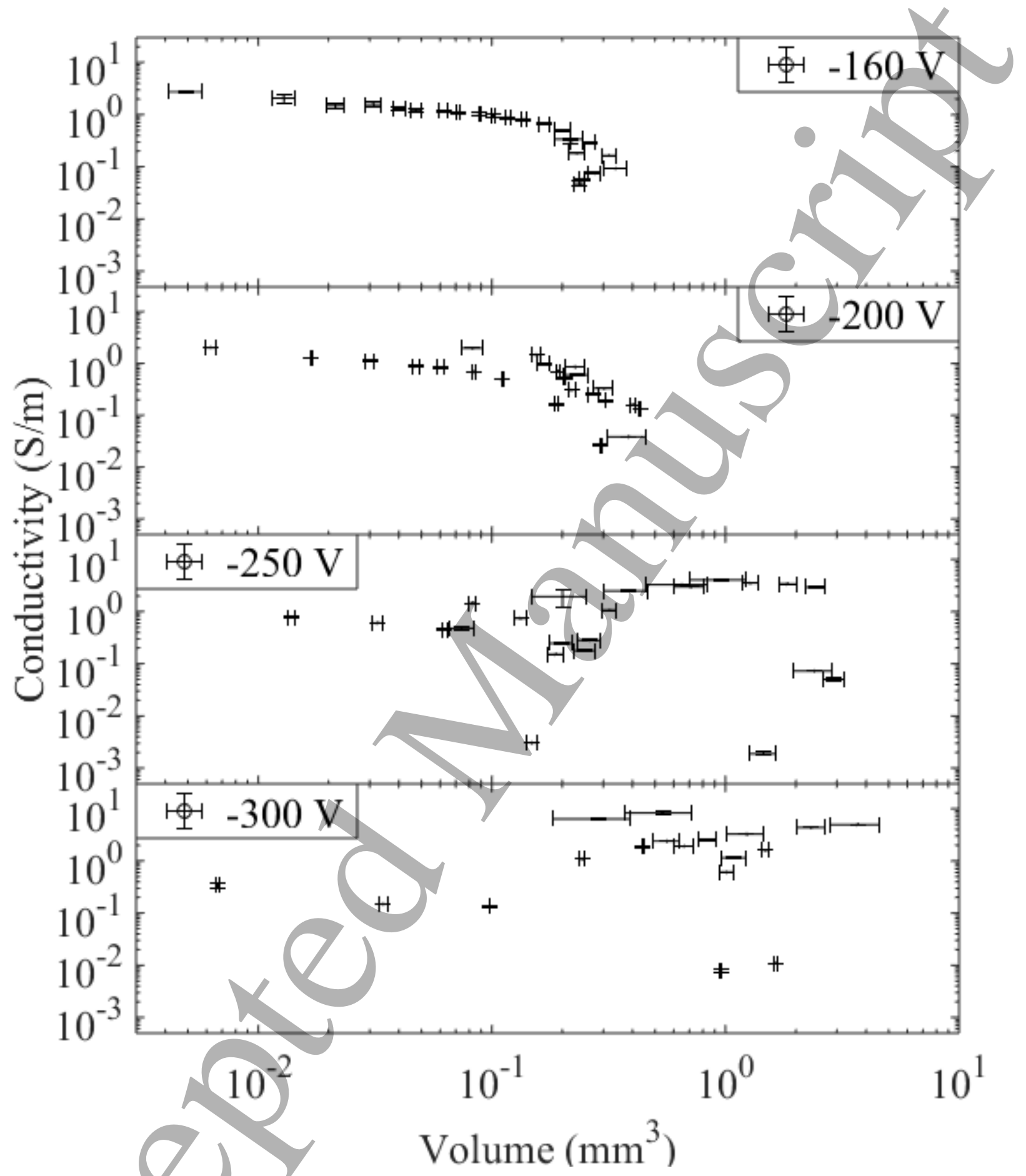

Figure 16. Conductivity values plotted against vapour volume for the applied voltages shown in figures $2,3,4$ and 5 .

left and right-hand sides of the vapour liquid interface. The differences in vapour volume calculation can be seen in the horizontal errorbars in figure 16 as noted above.

Some vapour conductivities are calculated to be greater than the conductivity of 
saline; for example, at $560 \mu$ s with $-300 \mathrm{~V}$ the vapour layer volume is $\sim 3.7 \mathrm{~mm}^{3}$ and the conductivity is estimated as $5.0 \mathrm{~S} / \mathrm{m}$, which is more than three times the conductivity of saline. Thus, in these cases of particularly high estimated conductivity the conductivities should be regarded as estimates of the average conductivity of the plasma discharge in the vapour layer.

The method of Woloszko et al. has been used here to estimate the number of electrons per unit volume in the discharges in the vapour layer [42]. This method can be used here assuming that in figure 16 the points with high volume and high conductivity have high conductivity because of plasma discharge in the vapour region. Thus, it is assumed the plasma conductivity can be estimated from the points with highest conductivity shown in figure 16. Typical estimated electric field values shown in figure 12 are in the range of $10^{4}$ to $10^{7} \mathrm{~V} / \mathrm{m}$. The particle number density in water vapour at $100{ }^{\circ} \mathrm{C}$ and 1 atmosphere pressure is estimated to be $\sim 2 \times 10^{25} \mathrm{~m}^{-3}$ from the ideal gas equation. The range of $E / N$ reduced electric field values calculated from these electric fields and this number density is 0.5 to $500 \mathrm{Td}$. Again from figure 12 the best estimate of the electric field that drives a discharge is $\sim 10^{6} \mathrm{~V} / \mathrm{m}$, which corresponds to a reduced electric field of $\sim 50 \mathrm{Td}$. The transport calculations of Ness et al. [58] suggest an electron drift velocity of $\sim 2 \times 10^{4} \mathrm{~m} / \mathrm{s}$ in water vapour at $50 \mathrm{Td}$. From these numbers the electron mobility, equal to the drift velocity divided by the electric field, is equal to $2 \times 10^{-2} \mathrm{~m}^{2} \mathrm{~V}^{-1} \mathrm{~s}^{-1}$.

The electron density, $n_{e}$, can be calculated from the measured conductivity, $\sigma$, the electron mobility, $\mu_{\mathrm{e}}$, and the charge on the electron, e, with

$$
n_{e}=\frac{\sigma}{\mathrm{e} \mu_{\mathrm{e}}}
$$

which gives an electron number density of $\sim 1.6 \times 10^{21} \mathrm{~m}^{-3}$.

The electron density during the discharges can also be estimated from the magnitude of the current, $I$, the drift velocity of the electrons, $v_{d}$ and the area through which the current passes, $A$.

$$
n_{e}=\frac{I}{\mathrm{e} v_{d} A}
$$

The discharge current is estimated as $\sim 0.3 \mathrm{~A}$ from the size of the discharge spikes in the current waveforms shown in figures $2,3,4$ and 5 . The drift velocity of the electrons is estimated above to be $2 \times 10^{4} \mathrm{~m} / \mathrm{s}$. The area through which the discharge passes is estimated to be $\sim 0.03 \mathrm{~mm}^{2}$ from the images of emission shown in figure 15 . With these values of discharge current/and discharge cross sectional area the electron density is estimated to be $\sim 3 \times 10^{21} \mathrm{~m}^{-3}$, which is very similar to the electron density estimated here above using the method of Woloszko et al.

The second method of electron density calculation in (7) is equivalent to the method used, for example, by Stark and Schoenbach [59].

The ratio between the expected particle density in the vapour layer and electron density indicates an ionization fraction of $\sim 10^{-4}$ during discharges in the vapour layer. 
The number densities of electrons estimated here are somewhat higher than the number densities obtained by Woloszko et al. who calculated values around $10^{18} \mathrm{~m}^{-3}$ [42]. In their experiment, Woloszko et al. drove their powered electrodes in saline with $100 \mathrm{kHz}$ square wave voltages with amplitudes up to $\pm 300 \mathrm{~V}$. By contrast, Yoon et al. determined a similar electron density of $\sim 5 \times 10^{20} \mathrm{~m}^{-3}$ from Stark broadening measurements in their experiment of RF discharge in different saline solutions [32].

Electron number densities for discharges in liquids have also been obtained by Bruggeman et al. [60] and Zheng et al. [61] in experiments where breakdown occurred between electrodes in liquid with bubbles of gas introduced between the electrodes. In both experiments tap water was used with lower conductivities than here in the range of $\sim 0.02$ to $0.06 \mathrm{~S} / \mathrm{m}$. Bruggeman et al. generated plasmas in bubbles of helium, argon and oxygen and determined electron densities of $10^{21}$ to $10^{23} \mathrm{~m}^{-3}$ by Stark broadening [60]. Zheng et al. introduced bubbles of nitrogen and observed calculated electron densities of $\sim 5 \times 10^{21} \mathrm{~m}^{-3}$ [61] with the second method used here as described by Stark and Schoenbach [59].

A similar calculation of charge carrier density can be made for the vapour region before discharge when the vapour conductivity appears to be abnormally high with (6). Using ion mobility of $2.15 \times 10^{-4} \mathrm{~m}^{2} \mathrm{~V}^{-1} \mathrm{~s}^{-1}$ for steam at $100{ }^{\circ} \mathrm{C}$ from Henson [62] ion densities of $10^{19}$ to $10^{22} \mathrm{~m}^{-3}$ are predicted assuming the observed conductivity is solely due to ions in the vapour region. Similarly, if it assumed that electrons alone give the observed conductivity the electron densities are predicted of $10^{17}$ to $10^{20} \mathrm{~m}^{-3}$. These predicted electron and ion densities are very high, particularly for the ions.

\section{Conclusions}

The present results focus on the growth of the 'vapour layer' around a small powered electrode immersed in saline solution following the application of a voltage pulse and prior to the initiation of electrical discharge. The exact nature of this vapour layer is not clear, but its growth has been clearly observed with a fast framing camera.

A simplistic model of the liquid in contact with the electrode is described here, which can be used as a 'rule of thumb' to predict the time taken for the vapour layer to grow before electrical discharge. Despite the evident simplifications of the model it provides good estimates for the time from application of the voltage pulse to the full development of the vapour layer, which are accurate to within $\sim 30 \%$ of the experimental results obtained here with no adjustable parameters.

An improved model of the vapour layer has been made by importing the geometry of the vapour liquid interface to a finite element modelling program along with the experimentally measured electrical impedance. It has been possible to calculate the effective conductivity of the vapour layer observed in each frame of the fast framing camera. Surprisingly high conductivities have been determined in the range of $10^{-3}$ to $10^{0} \mathrm{~S} / \mathrm{m}$, which are completely inconsistent with the expected value of $\sim 10^{-10} \mathrm{~S} / \mathrm{m}$ for water vapour at atmospheric pressure. The electric field and electrical potential in the 
vapour layer are also predicted with this improved model.

The reason for the high electrical conductivity of the vapour layer observed is not clear. Certainly a simple vapour layer of steam cannot account for the experimental observations. Charge carriers in the vapour layer could explain the high conductivity. These charge carriers could come from corona discharge at the sharp tip of the powered electrode and/or cluster ions such as $\left[\mathrm{Na}\left(\mathrm{H}_{2} \mathrm{O}\right)_{n}\right]^{+}$from the surrounding liquid, Consistently high electric fields of $10^{7} \mathrm{~V} / \mathrm{m}$ are calculated near the sharp tip that are consistent with corona discharge and previous observations of Na emission lines in similar experiments indicates that $\mathrm{Na}^{+}$ions will be present in the vapour layer. The high conductivity could, however, also be explained by the vapour layer being a 'foam' mixture of high conductivity liquid and low conductivity vapour bubbles.

The highest electric fields in the vapour layer of $\sim 10^{7} \mathrm{~V} / \mathrm{m}$ are predicted close to the sharp tip of the powered electrode, but the electric field strength drops to $\sim 10^{4}$ $\mathrm{V} / \mathrm{m}$ moving from the tip to the vapour liquid interface. A consistently high electric field of $\sim 10^{6} \mathrm{~V} / \mathrm{m}$ is calculated, however, between the side of the powered electrode and the vapour liquid interface where it approaches the electrode. Images of emission taken with fast framing camera indicate that emission from electrical discharge is observed at the side of the powered electrode where the consistently high electric field is calculated.

Further analysis of the estimated vapour conductivity and electric field calculated from images taken during electrical discharge have enabled the density of electrons in the discharge to be estimated by two different methods. Both methods indicated electron densities of $\sim 10^{21} \mathrm{~m}^{-3}$, which suggests the ionization fraction in the discharge is typically $\sim 10^{-4}$. Further work to try to establish the nature of the prebreakdown vapour layer has been started.

One final point to consider is the possibility of the formation of Taylor cones at the liquid vapour interface. The surface of the liquid will not charge up because the liquid has a high conductance and the liquid has the ground electrode inside it. When the vapour layer has a low conductivity, however, large potential differences can build up between the powered electrode and the vapour liquid interface, which could perhaps lead to Taylor cone formation. Indeed, in Figure 7, the shapes that look like bubbles could in fact be gaps in between Taylor cones. It is considered, however, more likely that these features are bubbles because the 'Taylor cones' are more pronounced at the lower applied voltage of $-160 \mathrm{~V}$ and it would be expected that they would be more pronounced at $-300 \mathrm{~V}$ where the electric fields are higher. Whether formed by bubbles or as Taylor cones it may be that droplets or ions are injected into the vapour from the edges or corners of these features that point towards the powered electrode.

\section{Acknowledgments}

The authors gratefully acknowledge transnational access support from the COST Action TD1208 'Electrical Discharges with Liquid for Future Applications'. The authors would also like to thank Mohammad Karim for his support. L Asimakoulas would like to 
thank Camlin Technologies Ltd for funding and technical assistance. L Dostal and F Krcma gratefully acknowledge grant CZ.02.1.01/0.0/0.0/16_013/0001638; CVVOZE Power Laboratories-modernization of research infrastructure.

\section{Appendix A. Vapour Conductivity and Electric Field Estimation}

The method used to estimate the vapour conductivity and electric field in the vapour layer from fast framing camera images is described here and shown diagrammatically in figure A1.

Frames from the video files acquired with the Fast Framing Camera (FFC) were converted with Matlab to binary black and white images so that boundaries could be seen clearly. At time zero the boundary between the liquid and the electrode tip can be seen. After time zero the boundary between the liquid and the vapour can be seen. Figure A1 (i) and (ii) show two representative raw images; (i) was taken at time zero and (ii) was taken at $280 \mu \mathrm{s}$; the red dotted lines indicate the cylindrical axis of symmetry. Figure A1 (iii) shows the same image at $280 \mu$ s as image (ii), but the left-hand side has been processed to black and white. Furthermore, the left-hand side of figure A1 (iii) also has calculated boundaries superimposed on the left-hand side; the red boundary is the liquid vapour boundary calculated from the left-hand side of this image at $280 \mu \mathrm{s}$ and the blue line indicates the boundary between the electrode and the vapour, which was determined from image (i) at time zero.

The Cartesian $(x, y)$ coordinates of the boundaries were stored individually for each frame with an extra independent variable $s$ as two parametric datasets, $y(s)$ and $x(s)$. COMSOL made a B-spline fit to these data points to generate continuous boundaries. The continuous boundaries were used in the model as interfaces between the electrode and the vapour and between the vapour and the liquid. In fitting the boundary of the electrode tip the minimum relative tolerance was set to $10^{-2}$ and for the liquidvapour boundaries the relative tolerance was set to $10^{-3}$. These tolerances were found to give good representations of the boundaries observed in the experiment and did not give abnormalities in the fitting procedure that would have caused disturbances in the electric potential and electric field calculations.

A cylinder, or a box in cylindrical symmetry, was used as the outer boundary for the model. The cylinder dimensions were radius $0.85 \mathrm{~mm}$ and height $1.7 \mathrm{~mm}$. The full $40 \mathrm{~mm}$ from/electrode to ground plate was not simulated in order to minimize the mesh elements computed and thus decrease the computational time needed to run the simulation. An electrical path to ground was provided by a resistor connected to the bottom and sides of the cylindrical box. This resistor simulated the effect of the liquid not considered in the simulation and its resistance was calculated from experimental data at time zero as described above.

To estimate the conductivity of the vapour it was assumed that the vapour conductivity was uniform. Different trial values of the conductivity were tested in the model to find the conductivity that gave the best 'impedance fit'. The impedance 
of the vapour and liquid was known experimentally for each frame from the electrical measurements of current and electrical potential (voltage) on the electrode. The solution time to test an individual conductivity for a single frame depended on the boundaries imported and varied from $5 \mathrm{~s}$ to $40 \mathrm{~s}$.

The mesh selected for the calculation was a general physics calibrated mesh with a minimum element size of $4.19 \times 10^{-6} \mathrm{~m}$ for the tungsten carbide tip and $6.28 \times 10^{-7} \mathrm{~m}$ for the rest of the geometry. Initially, a stationary direct MUMPS solver with a parametric sweep was used to run through all the imported boundaries for a fixed electric potential value.

Thus, as described above and in Section 3.4, the conductivity of the vapour layer was determined. With this vapour conductivity the finite element model could be used to determine the electrical potential, $\Phi$, at all positions in the vapour layer. The potential on the powered electrode was measured and known when each fast framing image was taken. Therefore, the electrical potential could be estimated with the model by applying the experimental potential to the powered electrode and calculating the current through the vapour layer and liquid layer using the calculated conductivity of the vapour layer, the known conductivity of the liquid, $1.61 \mathrm{~S} / \mathrm{m}$ as noted in Section 3.5 and the resistance between the outside of the model area and ground to simulate the liquid not considered in the model.

The electric field, E, can, of course, be calculated from the potential with

$$
\mathbf{E}=-\nabla \Phi
$$

which using cylindrical polar coordinates can be written as

or

$$
\mathbf{E}=-\left(\frac{\partial \Phi}{\partial r} \hat{\mathbf{r}}+\frac{1}{r} \frac{\partial \Phi}{\partial \phi} \hat{\boldsymbol{\phi}}+\frac{\partial \Phi}{\partial z} \hat{\mathbf{z}}\right)
$$

$$
\mathbf{E}=E_{r} \hat{\mathbf{r}}+E_{\phi} \hat{\boldsymbol{\phi}}+E_{z} \hat{\mathbf{z}}
$$

where $E_{r}, E_{\phi}$ and $E_{z}$ are the components of the electric field in the unit vector directions $\hat{\mathbf{r}}, \hat{\boldsymbol{\phi}}$ and $\hat{\mathbf{z}}$. The magnitude of the electric field, $|\mathbf{E}|$, can be calculated, of course, with

$$
|\mathbf{E}|=\sqrt{E_{r}^{2}+E_{\phi}^{2}+E_{z}^{2}}
$$

In cylindrical symmetry, of course, the component of Electric field in the direction $\hat{\phi}$, $E_{\phi}$ will be equal to zero.

The left-hand side of Figure A1(iv) shows the mesh used in the finite element calculation and the right-hand side shows the magnitude of the electric field determined.

For one set of data, shown in Figure 6, the procedure to find the electric field had to be slightly modified. The images recorded with the fast framing camera in Figure 6 did not cover the whole of the powered electrode so it was not possible to determine the conductance of the vapour layer in the normal way. In this case a typical value for the vapour conductivity just before discharge was taken. The experimentally measured potential was applied to the powered electrode in the simulation as described above to 
calculate the electrical potential distribution and then the electric field magnitude in the vapour region.

\section{References}

[1] Bruce R. Locke and Kai Yuan Shih. Review of the methods to form hydrogen peroxide in electrical discharge plasma with liquid water. Plasma Sources Science and Technology, 20(3), 2011.

[2] Bruce R. Locke. Environmental applications of electrical discharge plasma with liquid water - A mini review. International Journal of Plasma Environmental Science and Technology, 6(3):194203, 2012.

[3] S. Safa and G. Soucy. Liquid and solution treatment by thermal plasma: A review. International Journal of Environmental Science and Technology, 11(4):1165-1188, 2014.

[4] Qiang Chen, Junshuai Li, and Yongfeng Li. A review of plasma-liquid interactions for nanomaterial synthesis. Journal of Physics D: Applied Physics, 48(42), 2015.

[5] P J Bruggeman, M J Kushner, B R Locke, J G E Gardeniers, W G Graham, D B Graves, R C H M Hofman-Caris, D Maric, J P Reid, E Ceriani, D Fernandez Rivas, JE Foster, S C Garrick, Y Gorbanev, S Hamaguchi, F Iza, H Jablonowski, E Klimova, J Kolb, F Krcma, P Lukes, Z Machala, I Marinov, D Mariotti, S Mededovic Thagard, D Minakata, E C Neyts, J Pawlat, Z Lj Petrovic, R Pflieger, S Reuter, D C Schram, S Schröter, M Shiraiwa, B Tarabová, P A Tsai, J R R Verlet, T von Woedtke, K R Wilson, K Yasui, and G Zverevá. Plasmaliquid interactions: a review and roadmap. Plasma Sources Science and Technology, 25(5):053002, 2016.

[6] Susanta K Sen Gupta and Rajshree Singh. Cathodic eontact glow discharge electrolysis: its origin and non-faradaic chemical effects. Plasma Sources Science and Technology, 26(1):015005, 2016.

[7] N. A.H. Ramli, S. K. Zaaba, M. T. Mustaffa, A. Zakaria, and A. B. Shahriman. Review on the development of plasma discharge in liquid solution. In AIP Conference Proceedings, volume 1824. AIP Publishing, 2017.

[8] Peter J Bruggeman, Felipe Iza, and Ronny Brandenburg. Foundations of atmospheric pressure non- equilibrium plasmas. Plasma Sources Sci. Technol, 26:123002, 2017.

[9] Yang Cao, Guangzhou Qu, Tengfei Li, Nan Jiang, and Tiecheng Wang. Review on reactive species in water treatment using electrical discharge plasma: Formation, measurement, mechanisms and mass transfer. Plasma Science and Technology, 20(10):103001, 2018.

[10] Patrick Vanraes and Annemie Bogaerts. Plasma physics of liquids - A focused review. Applied Physics Reviews, 5(3):1-56, 2018.

[11] Davide Mariotti and R. Mohan Sankaran. Microplasmas for nanomaterials synthesis. Journal of Physics D: Applied Physics, 43(32):323001, 2010.

[12] W G Graham and K R Stalder. Plasmas in liquids and some of their applications in nanoscience. Journal of Physics D: Applied Physics, 44(17):174037, 2011.

[13] Hyun-jin Kim, Jun-goo Shin, Choon-sang Park, Dae Sub Kum, and Bhum Jae Shin. In-Liquid Plasma Process for Size- and Shape-Controlled Synthesis of Silver Nanoparticles by Controlling Gas Bubbles in Water. materials, 11(6):891, 2018.

[14] Malik Muhammad Arif, Ghaffar Abdul, and Malik Salman Akbar. Water purification by electrical discharges. Plasma Sources Science and Technology, 10(1):82, 2001.

[15] Masayuki Sato. Environmental and biotechnological applications of high-voltage pulsed discharges in water. Plasma Sources Science and Technology, 17(2):24021, 2008.

[16] A. Melhem, G. Henrion, T. Czerwiec, J. L. Briançon, T. Duchanoy, F. Brochard, and T. Belmonte. Changes induced by process parameters in oxide layers grown by the PEO process on Al alloys. Surface and Coatings Technology, 205(SUPPL. 2):S133-S136, 2011.

[17] S. C. Troughton, A. Nominé, A.V. Nominé, G. Henrion, and T.W. Clyne. Synchronised electrical monitoring and high speed video of bubble growth associated with individual discharges during plasma electrolytic oxidation. Applied Surface Science, 359:405-411, 2015.

[18] A. Nominé, S. C. Troughton, A. V. Nominé, G. Henrion, and T. W. Clyne. High speed video 
evidence for localised discharge cascades during plasma electrolytic oxidation. Surface and Coatings Technology, 269(1):125-130, 2015.

[19] Amin Hakimizad, Keyvan Raeissi, Mohammad Ali Golozar, Xiaopeng Lu, Carsten Blawert, and Mikhail L. Zheludkevich. Influence of cathodic duty cycle on the properties of tungsten containing Al2O3/TiO2PEO nano-composite coatings. Surface and Coatings Technology, 340(January):210-221, 2018.

[20] K R Stalder, D F McMillen, and J Woloszko. Electrosurgical Plasmas. J. Phys. D Appl. Phys., 38:1728-1738, 2005.

[21] K. R. Stalder and J. Woloszko. Some Physics and Chemistry of Electrosurgical Plasma Discharges. Contributions to Plasma Physics, 47(1-2):64-71, 2007.

[22] Yukinori Sakiyama, Takaaki Tomai, Masaru Miyano, and David B. Graves. Disinfection of E. coli by nonthermal microplasma electrolysis in normal saline solution. Applied Physics Letters, 94(16), 2009.

[23] Y. Huang, H. Yan, S. Li, and K. Yan. Multi-electrode electrohydraulic discharge for sterilization and disinfection. PPC2009 - 17th IEEE International Pulsed Power Conference, (1):886-891, 2009.

[24] Peter Bruggeman and Christophe Leys. Non-thermal plasmas in and in contact with liquids. Journal of Physics D: Applied Physics, 42(5):053001, 2009.

[25] Vladislav Gamaleev, Yo Okamura, Kensuke Kitamura, Yusuke Hashimoto, Jun-Seok Oh, Hiroshi Furuta, and Akimitsu Hatta. Investigation of microplasma discharge in sea water for optical emission spectroscopy. Japanese Journal of Applied Physics, 55(7S2):07LC03, 2016.

[26] Allen H. Olson. The physical mechanisms leading to electrical breakdown in underwater arc sound sources, 1993.

[27] Silvano Buogo and B. Giovanni Cannelli. Implosion of an underwater spark-generated bubble and acoustic energy evaluation using the Rayleigh model. The Journal of the Acoustical Society of America, 111:2594-2600, 2002.

[28] Vladislav Gamaleev, Jun Seok Oh, Hiroshi Furuta, and Akimitsu Hatta. Investigation of effect of needle electrode configuration on microplasma discharge process in sea water. IEEE Transactions on Plasma Science, 45(4):754-760, 2017.

[29] Matteo Gherardi, Nevena Puač, Dragana Marić, Augusto Stancampiano, Gordana Malović, Vittorio Colombo, and Zoran Lj Petrović. Practical and theoretical considerations on the use of ICCD imaging for the characterization of non-equilibrium plasmas. Plasma Sources Science and Technology, 24(6), 2015.

[30] Peng Xiao and David Staack. PMT and ICCD investigation of light emission from microplasma generated in liquid. In 19th IEEE Pulsed Power Conference, San Francisco, CA, USA, 2013. IEEE.

[31] Peng Xiao and David Staack. Microbubble generation by microplasma in water. Journal of Physics D: Applied Physics, 47(35):355203, 2014.

[32] Sung Young Yoon, Youn Chang Jang, Sang Heun Lee, Jung Wha Hong, Young Ki Hong, and Gon Ho Kim. Characteristics of vapor coverage formation on an RF-driven metal electrode to discharge a plasma in saline solution. Plasma Sources Science and Technology, 21(5):055017, 2012.

[33] Maria C. Garcia, Sarah N. Gucker, and John E. Foster. Understanding the plasma and power characteristics of a self-generated steam bubble discharge. Journal of Physics D: Applied Physics, 48(35):355203, 2015.

[34] Yalong Tu, Hualei Xia, Yong Yang, and Xinpei Lu. Time-resolved imaging of electrical discharge development in underwater bubbles. Physics of Plasmas, 23(1):013507, 2016.

[35] V. A. Panov, L. M. Vasilyak, S. P. Vetchinin, V. Ya Pecherkin, and E. E. Son. Pulsed electrical discharge in conductive solution. Journal of Physics D: Applied Physics, 49(38):385202, 2016.

[36] Roman Venger, Tetiana Tmenova, Flavien Valensi, Anatoly Veklich, Yann Cressault, and Viacheslav Boretskij. Detailed Investigation of the Electric Discharge Plasma between Copper

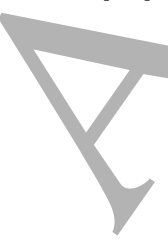
(1) 
Electrodes Immersed into Water. Atoms, 5(4):40, 2017.

[37] F Krcma, Z Kozakova, V Mazankova, J Horak, L Dostal, B Obradovic, A Nikiforov, and T Belmonte. Characterization of novel pin-hole based plasma source for generation of discharge in liquids supplied by DC non-pulsing voltage. Plasma Sources Sci. Technol, 27(065001):15, 2018.

[38] L. Schaper, W. G. Graham, and K. R. Stalder. Vapour layer formation by electrical discharges through electrically conducting liquids - Modelling and experiment. Plasma Sources Science and Technology, 20(3):034003, 2011.

[39] L. Schaper, C. P. Kelsey, P. Ceccato, A. Rousseau, K. R. Stalder, and W. G. Graham. Pre- to post-discharge behavior in saline solution. IEEE Transactions on Plasma Science, 39(11PART 1):2670-2671, 2011.

[40] L. Schaper, K. R. Stalder, and W. G. Graham. Plasma production in electrically conducting liquids. Plasma Sources Science and Technology, 20(3):034004, 2011.

[41] COMSOL Multiphysics@ v. 5.3. www.comsol.com. COMSOL AB, Stockholm, Sweden.

[42] Jean Woloszko, Kenneth R. Stalder, and Ian G. Brown. Plasma characteristics of repetitivelypulsed electrical discharges in saline solutions used for surgical procedures, 2002.

[43] Shiro Nukiyama. The maximum and minimum values of the heat $\mathrm{Q}$ transmitted from metal to boiling water under atmospheric pressure. International Journal of Heat and Mass Transfer, 9(12):1419-1433, 1966.

[44] Yunus A. Cengel. Heat transfer:A practical approach. McGraw-Hill, 2002.

[45] Y. D. Korolev, I. A. Shemyakin, R. V. Ivashov, V. S. Kasyanov, N. V. Landl, Y. H. Sun, T. Shao, and Y. Gao. Discharge in the saline solutions in a vicinity of the threshold voltages. Journal of Physics: Conference Series, 552(1):012005, 2014.

[46] S. Yu Shadrin and P. N. Belkin. Analysis of models for calculation of temperature of anode plasma electrolytic heating. International Journal of Heat and Mass Transfer, 55(1-3):179-186, 2012.

[47] A L Yerokhin, X Nie, A Leyland, A Matthews, and S J Dowey. Plasma electrolysis for surface engineering. Surface and Coatings Technology, 122:73-93, 1999.

[48] E. Colin W Clarke and David N. Glew. Erratum: Evaluation of the Thermodynamic Functions for Aqueous Sodium Chloride from Equilibrium and Calorimetric Measurements below $154 \mathrm{C}$ [J. Phys. Chem. Ref. Data 14, 489 (1985)]. Journal of Physical and Chemical Reference Data, 18(1):545-550, 1989.

[49] M Laliberte and W E Cooper. Model for calculating the density of aqueous electrolyte solutions. Journal of Chemical and Engineering Data, 49(5):1141-1151, 2004.

[50] Daniel Palanker, Alexander Vankov, and Pradeep Jayaraman. On mechanisms of interaction in electrosurgery. New journal of physics, 10(12):123022, 2008.

[51] N. G. Chondrakis and F. V. Topalis. Evaluation of heat transfer coefficient of tungsten filaments at low pressures and high temperatures. Applied Thermal Engineering, 31(2-3):258-267, 2011.

[52] P. Tolias. Analytical expressions for thermophysical properties of solid and liquid tungsten relevant for fusion applications. Nuclear Materials and Energy, 13:42-57, 2017.

[53] P. Bruggeman, J. Degroote, C. Leys, and J. Vierendeels. Plasma characteristics in air and vapor bubbles in water. The 28th International Conference on Phenomena in Ionized Gases, pages 859-862, 2007.

[54] Peter Bruggeman, Joris Degroote, Jan Vierendeels, and Christophe Leys. DC-excited discharges in vapour bubbles in capillaries. Plasma Sources Science and Technology, 17(2):025008, 2008.

[55] Ranhua Xiong, Anton Yu Nikiforov, Patrick Vanraes, and Christophe Leys. Characteristics of an underwater direct current discharge in bubbles and the temperature distribution in the bubbles. Physics of Plasmas, 19(2):023501, 2012.

[56] Chao-Yu Sie, Hung-Wen Chang, and Cheng-Che Hsu. Tungsten electrode erosion by microplasmas in saline solution. Journal of The Electrochemical Society, 158(5):E37-E40, 2011.

[57] Xu Yang, Xianfei Ding, Guojian Hao, Yongfeng Liang, and Junping Lin. Cathodic Plasma Electrolysis Processing for Metal Coating Deposition. Plasma Chemistry and Plasma Processing, 

37(1):177-187, 2017.

[58] K. F. Ness, R. E. Robson, M. J. Brunger, and R. D. White. Transport coefficients and cross sections for electrons in water vapour: Comparison of cross section sets using an improved Boltzmann equation solution. Journal of Chemical Physics, 136(2):024318, 2012.

[59] Robert H Stark and Karl H Schoenbach. Direct current glow discharges in atmospheric air. Applied Physics Letters, 74(25):3770-3772, 1999.

[60] Peter Bruggeman, Tiny Verreycken, Manuel A Gonzalez, James L Walsh, Michael G Kong, Christophe Leys, and Daan C Schram. Optical emission spectroscopy as a diagnostic for plasmas in liquids: opportunities and pitfalls. Journal of Physics D: Applied Physics, 43(12):124005, 2010.

[61] SJ Zheng, YC Zhang, B Ke, F Ding, ZL Tang, K Yang, and XD Zhu. Dynamic characteristics of gas-water interfacial plasma under water. Physics of Plasmas, 19(6):063507, 2012.

[62] Bob L Henson. Ion mobilities in pure water vapour at saturation. Journal of Physics D: Applied Physics, 11(10):1405, 1978. 

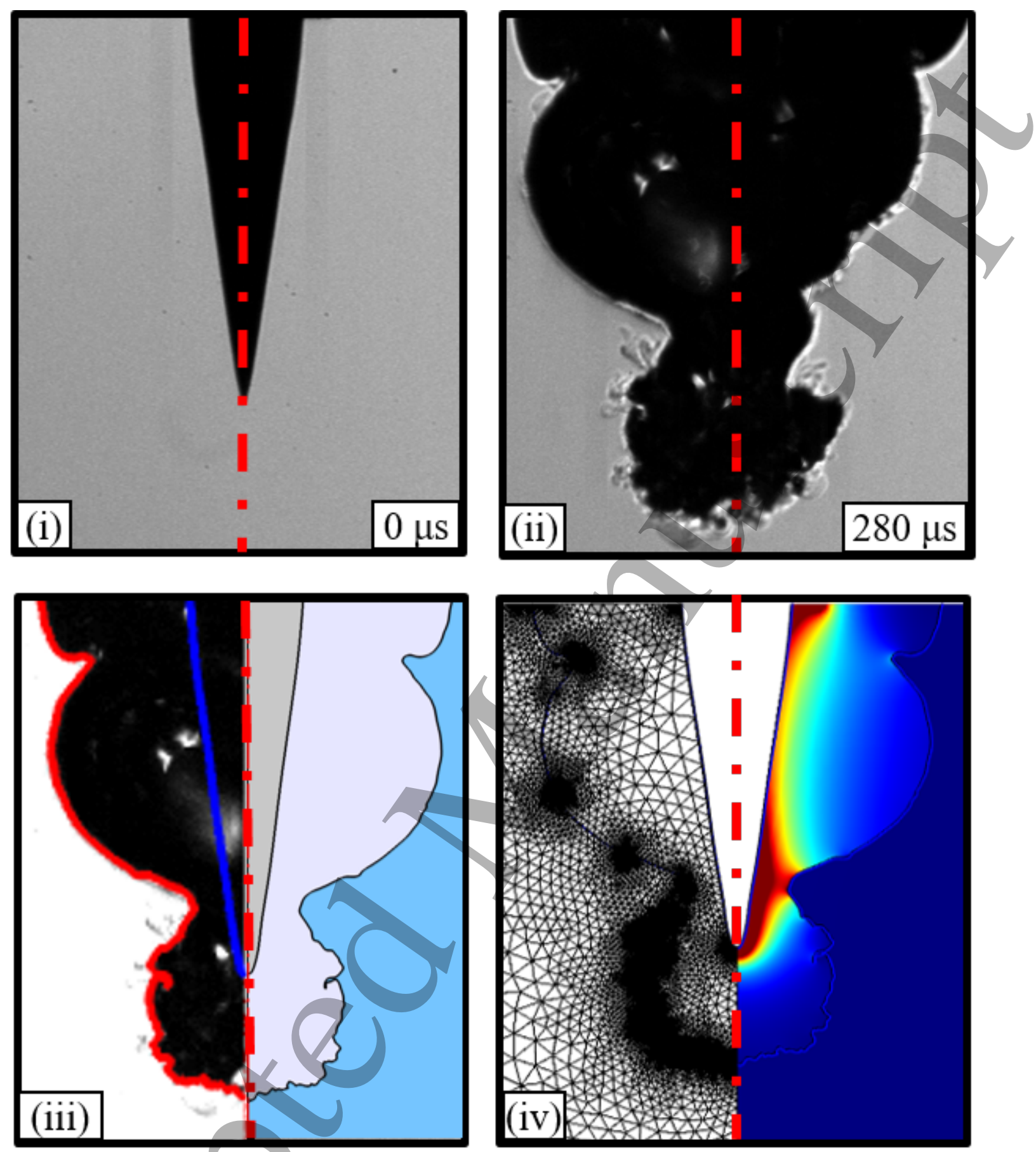

Figure A1. Outline of the procedure that was followed to calculate conductivity and electric fields inside the vapour layer. (i) Image taken at time zero, which shows the position of the electrode tip with no vapour layer. (ii) Image taken at $280 \mu \mathrm{s}$ at -300 $\mathrm{V}$; a typical frame with vapour around the tip. Note the variation between the left and right side of the image. (iii) On the left side the liquid vapour boundary is shown in red and the edge of the electrode tip position is blue; the right-hand side shows the liquid, vapour and electrode regions. (iv) The left-hand side shows the mesh that was used for this geometry and the right-hand side shows a map of calculated electric field strengths. The dotted red vertical lines indicate the axes of cylindrical symmetry. 